\title{
Technical Review of the UNET2D Hydraulic Model
}

\author{
W. A. Perkins \\ M. C. Richmond \\ Hydrology Group \\ Pacific Northwest National Laboratory \\ Richland, WA 99352 \\ Prepared for: \\ US Army Corps of Engineers, Kansas City District \\ Kansas City, MO
}

May 18, 2009 


\title{
DISCLAIMER
}

This report was prepared as an account of work sponsored by an agency of the United States Government. Neither the United States Government nor any agency thereof, nor Battelle Memorial Institute, nor any of their employees, makes any warranty, express or implied, or assumes any legal liability or responsibility for the accuracy, completeness, or usefulness of any information, apparatus, product, or process disclosed, or represents that its use would not infringe privately owned rights. Reference herein to any specific commercial product, process, or service by trade name, trademark, manufacturer, or otherwise does not necessarily constitute or imply its endorsement, recommendation, or favoring by the United States Government or any agency thereof, or Battelle Memorial Institute. The views and opinions of authors expressed herein do not necessarily state or reflect those of the United States Government or any agency thereof.

\author{
PACIFIC NORTHWEST NATIONAL LABORATORY \\ operated by \\ BATTELLE \\ for the \\ UNITED STATES DEPARTMENT OF ENERGY \\ under Contract DE-AC05-76RL01830
}

Printed in the United States of America
Available to DOE and DOE contractors from the Office of Scientific and Technical Information,
P.O. Box 62, Oak Ridge, TN 37831-0062;
ph: (865) 576-8401
fax: $(865) 576-5728$
email: reports@adonis.osti.gov

\footnotetext{
Available to the public from the National Technical Information Service, U.S. Department of Commerce, 5285 Port Royal Rd., Springfield, VA 22161 ph: (800) 553-6847 fax: $(703) 605-6900$ email: orders@ntis.fedworld.gov online ordering: http://www.ntis.gov/ordering.htm
}

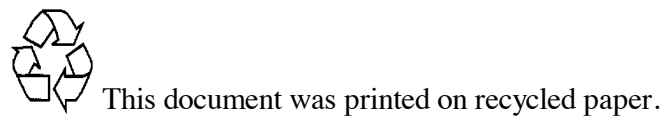


PNNL-18416

\title{
Technical Review of the UNET2D Hydraulic Model
}

\author{
W. A. Perkins \\ M. C. Richmond \\ Hydrology Group \\ Pacific Northwest National Laboratory \\ Richland, WA 99352
}

Prepared for:

U.S.Army Corps of Engineers, Kansas City District Kansas City, MO

May 18, 2009 



\section{Executive Summary}

The Kansas City District of the US Army Corps of Engineers is engaged in a broad range of river management projects that require knowledge of spatially-varied hydraulic conditions such as velocities and water surface elevations. This information is needed to design new structures, improve existing operations, and assess aquatic habitat. Two-dimensional (2D) depth-averaged numerical hydraulic models are a common tool that can be used to provide velocity and depth information. Kansas City District is currently using a specific 2D model, UNET2D, that has been developed to meet the needs of their river engineering applications. This report documents a technical review of UNET2D.

The UNET2D model documentation was reviewed to assess the theoretical basis of the model, numerical methods utilized, and the applicability of the model to analyze river engineering problems of interest to Kansas City District. In addition, UNET2D was subjected to a series of simulation tests performed by Pacific Northwest National Laboratory (PNNL) staff. The simulation results were either compared to theory or experimental results when available, or to simulations performed with the PNNL 2D depth-averaged model, the Modular Aquatic Simulation System in 2 Dimensions (MASS2), was applied to some of the tests for comparison purposes.

UNET2D uses a set of novel methods to derive, discretize, and solve the 2D depth-averaged equations of fluid flow. If implemented correctly and consistently these methods are expected to yield solutions that would be consistent with those produced by similar $2 \mathrm{D}$ depth-averaged hydraulic models. However, several potential problems with the theory and numerical implementation were noted and may be the source of the problems that were encountered with some of the test cases.

UNET2D adequately simulated fluid flow in the subcritical, uniform flow when the mesh rectilinear and consisted of a single loop, the depth was above $7.5 \mathrm{ft}$, and wetting and drying was not enabled or not an issue. Otherwise, fluid flow simulation was problematic. The UNET2D wetting and drying algorithm had a very large, adverse effect on the representation of fluid flow. Also, UNET2D was unable, but should be able, to simulate fluid flow at laboratory scale.

We do not recommend the use of the tested version of UNET2D for hydraulic engineering or aquatic habitat studies at this time. The number and nature of the problems with the tested version of UNET2D indicates that further development and testing must be done before the code can be used with confidence.

Based in part on the results shown in this report that were shared in project status meetings, further UNET2D development and testing has been ongoing and some of the problems reported here have been corrected. The code documentation for the theory, numerical methods, and validation cases should be updated and reviewed. An external review may not be required and could possibly be performed by Kansas City District hydraulic engineers that have not been involved in the code development and testing work. 



\section{Contents}

Executive Summary . . . . . . . . . . . . . . . . . iii

1 Introduction . . . . . . . . . . . . . . . . . . . 1

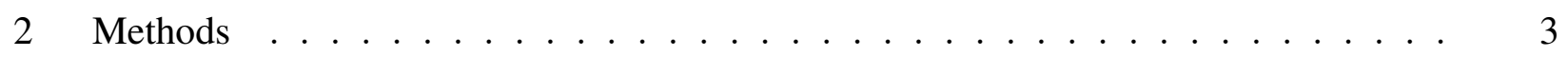

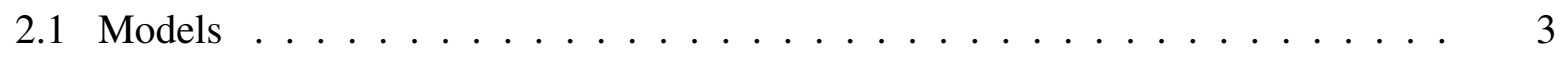

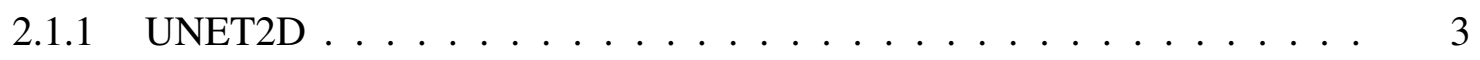

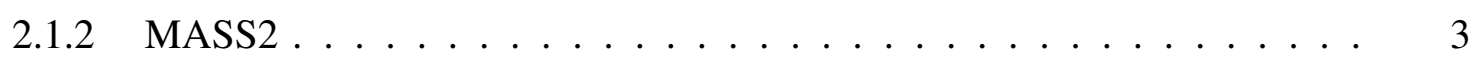

2.2 Test Cases . . . . . . . . . . . . . . . . . . . . . . 4

2.2.1 Subcritical, Uniform Flow in a Rectangular Channel . . . . . . . . . . . 4

2.2 .2 Uniform Flow in a Trapezoidal Channel . . . . . . . . . . . . . . . . . 4

2.2 .3 Flow Around a Spur-Dike . . . . . . . . . . . . . . 5

2.2 .4 Flow in a 180 -degree Bend . . . . . . . . . . . . 6

2.2 .5 Jameson Bend . . . . . . . . . . . . . . . . 7

3 Results and Discussion . . . . . . . . . . . . . . . . . . . . 13

3.1 Review of Theoretical Basis and Numerical Methods . . . . . . . . . . . . . 13

3.1 .1 Coordinate System and Governing Equations . . . . . . . . . . . . . 13

3.1 .2 Numerical Solution Methods . . . . . . . . . . . . . . . . . . . 14

3.2 Subcritical, Uniform Flow in a Rectangular Channel . . . . . . . . . . . . . . . 14

3.3 Uniform Flow in a Trapezoidal Channel . . . . . . . . . . . . . . . . . 15

3.4 Flow Around a Spur-Dike . . . . . . . . . . . . . . . . . 15

3.5 Flow in a 180 -degree Bend . . . . . . . . . . . . . . . . 18

3.6 Jameson Bend $\ldots \ldots \ldots \ldots$

4 Conclusions and Recommendations $\ldots \ldots$. . . . . . . . . . . . . . . . 29 
4.1 Conclusions . . . . . . . . . . . . . . . . . . . . . . . 29

4.2 Recommendations . . . . . . . . . . . . . . . . . . . . . 29

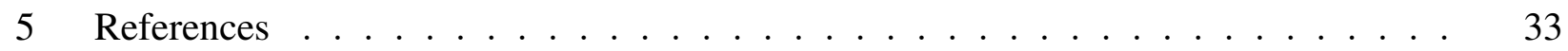




\section{Figures}

$2.1 \quad$ Dimensions of the uniform flow in a rectangular channel test. . . . . . . . . . . 5

2.2 Channel cross section dimensions in the uniform flow in a trapezoidal channel test. 5

$2.3 \quad$ Layout of flow around a spur-dike test (at laboratory scale). . . . . . . . . . . . 6

$2.4 \quad$ Layout of the flow in a 180-degree bend test (planview at laboratory scale). . . . . . 7

\begin{tabular}{|lll}
\hline 2.5 & The area around Jameson Island along the Missouri River near Arrow Rock, \\
\hline & Missouri (source: U.S. Army Corps of Engineers, Kansas City District). . . . . . . & 9
\end{tabular}

2.6 Mesh and bathymetry used for simulation of Jameson Bend. . . . . . . . . . . . . 10

2.7 MASS2 mesh detail at the upstream end of the Jameson Bend chute. The downstream end of the chute mesh was connected to the main channel mesh in a similar manner. . . . . . . . . . . . . . . . . . 11

3.1 Simulated flow around a spur-dike from MASS2 and UNET2D with various values of eddy viscosity $\left(v_{t}, \mathrm{ft}^{2} / \mathrm{s}\right)$. The red line divides positive and negative longitudinal velocity, identifying the recirculation zone behind the dike. . . . . 17

3.2 Comparison of simulated depth(ft) from MASS2 (top panel) and UNET2D (bottom panel) in the flow in a 180-degree bend test. . . . . . . . . . . . . . . 19

3.3 Comparison of simulated velocity (ft/s) magnitude from MASS2 (top panel) and UNET2D (bottom panel) in the flow in a 180-degree bend test. . . . . . . . . . 19

3.4 Comparison of depth (ft) simulated by MASS2 and UNET2D with literature for flow in a 180-degree bend test. . . . . . . . . . . . . . . . 20

3.5 Comparison of velocity (ft/s) simulated by MASS2 and UNET2D with an example from literature for flow in a 180-degree bend test. $\ldots . . . . . . .21$

3.6 Comparison of simulated depth (ft) from UNET2D with wetting and drying disabled (top panel) and with wetting and drying enabled (bottom panel) in the flow in a 180-degree bend test. . . . . . . . . . . . . . . 22

3.7 Comparison of MASS2 (left) and UNET2D (right) simulated depth (ft, top) and velocity (ft/s, bottom) in the Jameson Bend case. The numbered circles denote areas of interest discussed in the text. . . . . . . . . . . . . 25

3.8 Velocity magnitude (ft/s) simulated by UNET2D in the Missouri River downstream of Jameson Island. . . . . . . . . . . . . . . . . . . . . 26 
3.9 Comparison of MASS2 (left) and UNET2D (right) simulated depth (ft, top) and velocity (ft/s, bottom) in the Jameson Bend case (with planned chute). The
numbered circles denote areas of interest discussed in the text. . . . . . . . . 27

3.10 Comparison of MASS2 simulated velocity using a computed (equation 2.1) and \begin{tabular}{l|r} 
large constant eddy viscosity $\left(100 \mathrm{ft}^{2} / \mathrm{s}\right)$ in Jameson Bend just downstream of the bar. & 28
\end{tabular} 


\section{Tables}

2.1 Simulation cases attempted in the uniform flow in a trapezoidal channel test. A bulk velocity of $2.0 \mathrm{ft} / \mathrm{s}$ was used in all cases. . . . . . . . . . . . . . . . . 5

3.1 Simulated cases of uniform flow in a rectangular channel with and without wet-

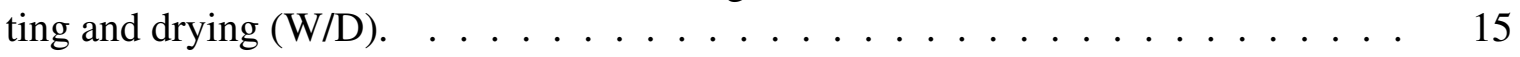





\subsection{Introduction}

The Kansas City District of the US Army Corps of Engineers is engaged in a broad range of river management projects that require knowledge of spatially-varied hydraulic conditions such as velocities and water surface elevations. This information is needed to design new structures, improve existing operations, and assess aquatic habitat. Two-dimensional (2D) depth-averaged numerical hydraulic models are a common tool that can be used to provide velocity and depth information.

Kansas City District is currently using a specific 2D model, UNET2D, that has been developed to meet the needs of their river engineering applications. At the request of the Kansas City District, Pacific Northwest National Laboratory (PNNL) Hydrology Group has conducted an independent technical review of the UNET2D model. This report documents that review.

PNNL is able to provide this support to the Kansas City District because the Laboratory has extensive experience in the development and application of 2D depth-averaged hydraulic models for use in assessing the impacts of hydroelectric dam operations to water quality, navigation, and fisheries issues in the Columbia River Basin.

The UNET2D model documentation was reviewed to assess the theoretical basis of the model, numerical methods utilized, and the applicability of the model to analyze river engineering problems of interest to Kansas City District.

In addition, UNET2D was subjected to a series of simulation tests performed by PNNL staff. The simulation results were either compared to theory or experimental results when available. In addition, a PNNL two-dimensional, depth-averaged model, the Modular Aquatic Simulation System in 2 Dimensions (MASS2), was applied to some of the tests for comparison purposes.

This review was conducted using a specific version of UNET2D, obtained from Kansas City District staff on September 25, 2008. Model development subsequent to that version almost certainly has, or will, alter the results and conclusions of this review. 



\subsection{Methods}

\subsection{Models}

\subsubsection{UNET2D}

The UNET2D version used for this work was obtained from Kansas City District personnel during a meeting held in Richland, Washington on September 25, 2008. Two Excel spreadsheets were supplied. The first, named Sierra2D_Ver1.01.xls, was the complete code. The second, Sierra2D_Ver1.01withoutPC.xls, had the wetting and drying algorithm disabled, and thus could only be used for problems in which the domain was entirely inundated.

UNET2D simulations were performed using a Dell Dimension 670 workstation with 4 Intel Xeon cores operating at $3.39 \mathrm{GHz}$. The system had Windows XP Professional 2002 SP2 installed with all recent updates. Windows Office Excel 2003 (11.8231.8221) SP3 was used to run UNET2D.

\subsubsection{MASS2}

The Modular Aquatic Simulation System in 2 Dimensions (MASS2) was developed at Pacific Northwest National Laboratory (Perkins and Richmond 2004a b) and has been applied to a variety of river and estuarine flow (Richmond et al.|1999a, Rakowski and Richmond 2001, 2003, Rakowski] et al. 2008), water quality (Richmond et al.1999b c, 2000, Kincaid et al.2001) and aquatic habitat (McMichael et al. 2003, Perkins et al. 2004, Hanrahan et al.2007) problems.

MASS2 is formulated using the general finite-volume principles described by Patankar (1980). The model uses a structured multi-block scheme utilizing a curvilinear computational mesh. Spasojevic and Holly (1990) give an example of a two-dimensional model of this type. The coupling of the momentum and mass conservation equations is achieved using a variation of Patankar (1980) SIMPLE algorithm extended to shallow-water flows by Zhou (1995). In MASS2, Zhou's method has been applied to orthogonal curvilinear coordinates. In the method, the continuity equation is discretized and solved for a depth correction, in lieu of the pressure correction in the original SIMPLE algorithm. The solution to the depth correction equation is used to correct the estimated velocity from the solution of the momentum equations. A portion of the depth correction is used to adjust depth.

The MASS2 code is written in Fortran95 and compiles on Linux, Mac OS X, and Windows systems.

A recently added feature of MASS2 used in this work is the ability to compute a spatially varying eddy viscosity (not documented by Perkins and Richmond 2004a). The method is based on theory of mixing in rivers (Fischer et al. 1979) and is common to several other two-dimensional, depthaveraged flow models (e.g., Zhou 1995, Lien et al. 1999, Duan 2004, Hadian and Zarrati 2008). The spatially varying (kinematic) turbulent eddy viscosity, $v_{t}$, is

$$
v_{t}=v+\frac{\kappa}{6} \overline{U_{*}} d
$$

where $v$ is the kinematic viscosity of water, $\kappa$ is the von Karman constant (0.4), $d$ is the depth, and 
$\overline{U_{*}}$ is the shear velocity, given by (Lien et al. 1999)

$$
\overline{U_{*}}=\left(\frac{\tau_{b}}{\rho}\right)^{\frac{1}{2}}
$$

and $\tau_{b}$ is the magnitude of the bed shear stress,

$$
\tau_{b}=\left(\tau_{b 1}^{2}+\tau_{b 2}^{2}\right)^{\frac{1}{2}}
$$

The bed shear stress components are computed using

$$
\tau_{b 1}=\rho C_{b} U \sqrt{U^{2}+V^{2}}
$$

and

$$
\tau_{b 2}=\rho C_{b} V \sqrt{U^{2}+V^{2}}
$$

where the bed-friction coefficient is calculated based on the Manning roughness value, $n$, as

$$
C_{b}=g\left(\frac{n^{2}}{1.49 d^{1 / 3}}\right)
$$

\subsection{Test Cases}

\subsubsection{Subcritical, Uniform Flow in a Rectangular Channel}

This test was used to verify that UNET2D was able simulate sub-critical, uniform open channel flow. This test was intended to isolate and validate the representation of friction and gravity forces.

UNET2D was configured to simulate a rectangular channel $10,000 \mathrm{ft}$ long and $500 \mathrm{ft}$ wide. An bulk velocity of $2.0 \mathrm{ft} / \mathrm{sec}$ and a slope of $1.4245 \times 10^{-4}$ were chosen (Figure 2.1). This results in a Chezy coefficient of 61.2. Note that the Chezy coefficient was computed using depth rather than wetted perimeter, consistent with the representation of bottom friction in UNET2D.

The mesh used was 100 cells long by 10 cells wide. The normal depth was imposed as the downstream boundary condition. Six cases were simulated with normal depths of 2.5, 5.0, 7.5, 10.0, 15.0 , and $20.0 \mathrm{ft}$. A constant discharge that would produce a bulk velocity of $2.0 \mathrm{ft} / \mathrm{s}$ was applied at the upstream boundary. A simulation time step of $60 \mathrm{~s}$ was used and the simulation was run for $21600 \mathrm{~s}$ in each case.

\subsubsection{Uniform Flow in a Trapezoidal Channel}

As in Section 2.2.1, this test was used to verify that UNET2D was able to simulate sub-critical, uniform open channel flow. In this case, however a trapezoidal channel cross section was used. In addition to validating friction and gravity forces, this test included the wetting and drying algorithm. A successful simulation of this test would indicate that the wetting and drying algorithm worked and did not interfere with the accurate representation of friction. 


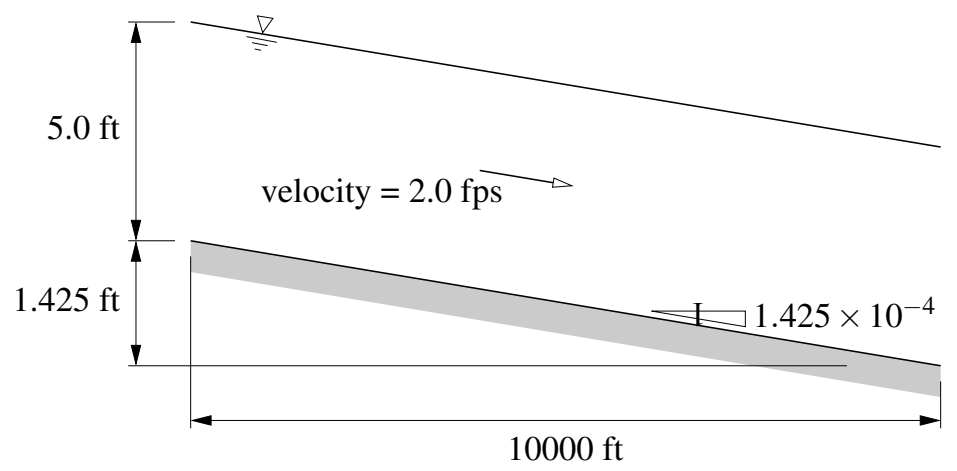

Figure 2.1. Dimensions of the uniform flow in a rectangular channel test.

UNET2D was configured to simulate a trapezoidal channel (cross section dimensions are shown in Figure 2.2 $5000 \mathrm{ft}$ long with a bed slope of $5 \times 10^{-7}$. The mesh was 34 cells wide by 100 cells long. Several normal depths were tried, as shown in Table 2.1. The depth at the downstream boundary was intially $35 \mathrm{ft}$ then ramped to the normal depth over $7200 \mathrm{~s}$. The discharge required to produce a bulk velocity of $2.0 \mathrm{ft} / \mathrm{s}$ was imposed at the upstream boundary.

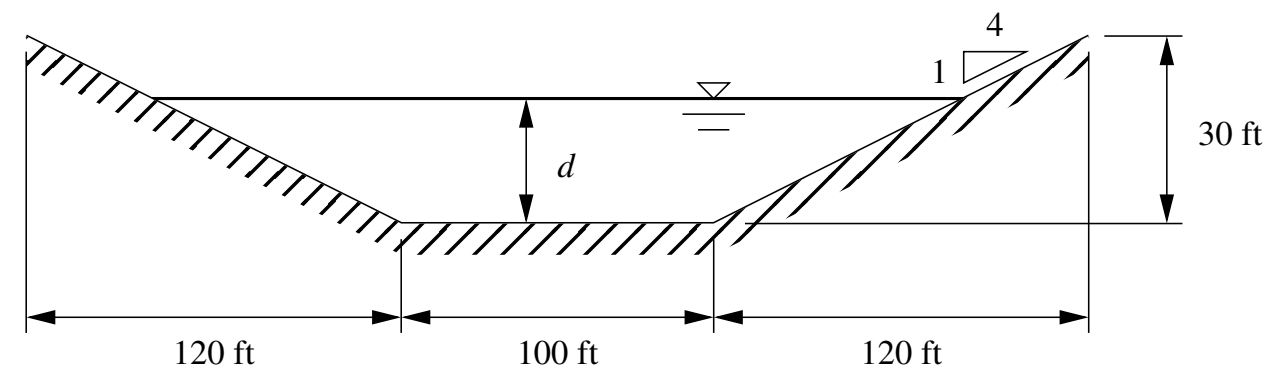

Figure 2.2. Channel cross section dimensions in the uniform flow in a trapezoidal channel test.

Table 2.1. Simulation cases attempted in the uniform flow in a trapezoidal channel test. A bulk velocity of $2.0 \mathrm{ft} / \mathrm{s}$ was used in all cases.

\begin{tabular}{ccrrrr}
\hline \hline Case & $d, \mathrm{ft}$ & $R, \mathrm{ft}$ & $C$ & $A, \mathrm{ft}^{2} / \mathrm{s}$ & $Q, \mathrm{ft}^{3} / \mathrm{s}$ \\
\hline 1 & 25 & 211.8 & 194.3 & 5000 & 10000 \\
2 & 15 & 167.1 & 218.8 & 2400 & 4800 \\
3 & 7.5 & 133.5 & 244.8 & 975 & 1950 \\
4 & 5.0 & 122.4 & 255.7 & 600 & 1200 \\
\hline \hline
\end{tabular}

\subsubsection{Flow Around a Spur-Dike}

Flow around a spur-dike, or groyne, has been used in several studies to verify hydrodynamic models (Ouillon and Dartus 1997, Tingsanchali and Maheswaran 1990, Molls and Chaudhry 1995). Tingsanchali and Maheswaran (1990), Molls and Chaudhry (1995) and Molls et al. (1995) compared simulations to the data of Rajaratnam and Nwachukwu (1983) and Nawachukwu (1979). Ouillon and Dartus (1997) compared simulation against another set of experimental data. This test simulates the experimental work done by Rajaratnam and Nwachukwu (1983). This test is 
also part of the MASS2 validation suite (Perkins and Richmond 2004a).

The dimensions of the laboratory experiment are shown in Figure 2.3. UNET2D was initially configured to simulate the laboratory scale problem, but was not able to do so. In order get a working simulation, the problem was Froude-scaled by 25, so that the depth was $15.5 \mathrm{ft}$ and the bulk velocity was $4.15 \mathrm{ft} / \mathrm{s}$.

The mesh used was 216 cells long by 36 cells wide. A constant depth of $15.5 \mathrm{ft}$ was imposed at the downstream boundary. At the upstream, the imposed discharge was initially zero for $300 \mathrm{~s}$ then ramped up to $4749 \mathrm{cfs}$ over $300 \mathrm{~s}$. The spur-dike was represented as a dike with the top elevation well above the water surface. A Chezy coefficient of 137 was used. Several values of eddy viscosity were tried. Each case was simulated for $7200 \mathrm{~s}$ with a $5 \mathrm{~s}$ time step with wetting and drying enabled.

MASS2 was also used to simulate the scaled test for comparison purposes. A mesh very close to the UNET2D mesh was used. The spur-dike was represented as a very thin plate using a wall internal boundary. The eddy viscosity used in the laboratory scale simulation by Perkins and Richmond (2004a) (1.61e-02 $\left.\mathrm{ft}^{2} / \mathrm{sec}\right)$ was scaled up to $2.0 \mathrm{ft}^{2} / \mathrm{sec}$. The Manning's roughness coefficient was also scaled up from 0.010 to 0.017 . MASS2 simulated about $1 \mathrm{hr}$ using a time step of $10 \mathrm{~s}$ and the upwind advection scheme was used.

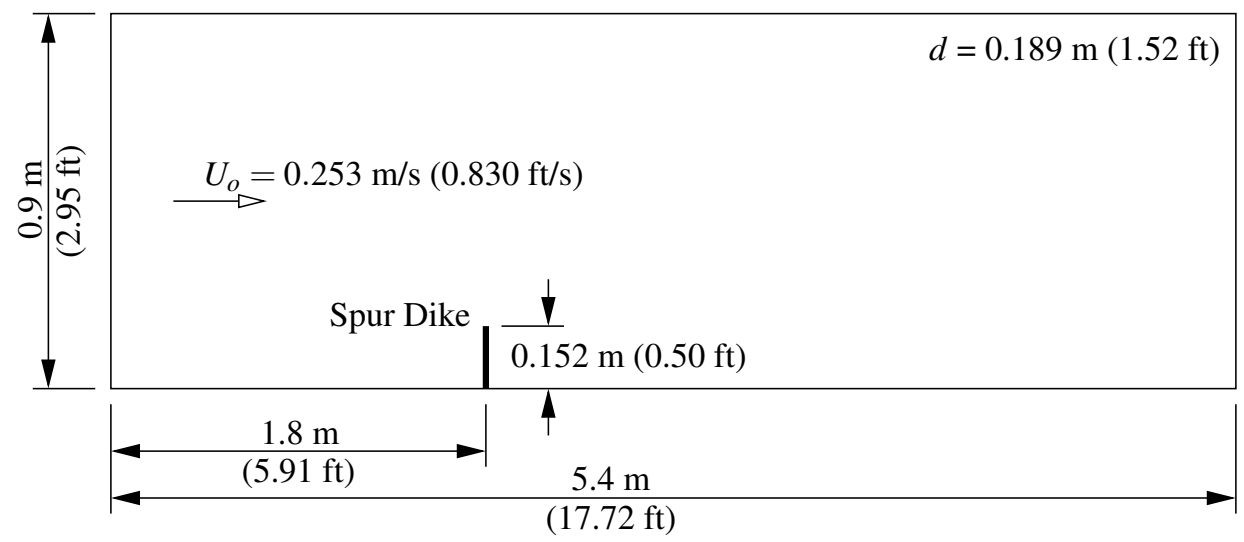

Figure 2.3. Layout of flow around a spur-dike test (at laboratory scale).

\subsubsection{Flow in a 180-degree Bend}

In this test, the laboratory experiment of Rozovskii (1957) was simulated. This data set has been commonly used to validate two-dimensional, depth-averaged models (for example Molls and Chaudhry 1995, Lien et al. 1999, Duan 2004). The layout of the experiment is shown in Figure 2.4.

Initial attempts to simulate this case with UNET2D at laboratory scale produced obviously incorrect results, so as in Section 2.2.3, the problem was Froude-scaled up by 25. This resulted in an expected depth of $4.79 \mathrm{ft}$ and bulk velocity of $4.347 \mathrm{ft} / \mathrm{s}$.

The UNET2D mesh consisted of 5 loops each 20 cells wide and totaling 108 cells longitudinally. 
The Chezy coefficient was set to 109 (as did Lien et al. 1999). A depth of $4.55 \mathrm{ft}$ was imposed at the downstream boundary and a constant discharge of $1366.3 \mathrm{cfs}$ was imposed upstream. Eddy viscosity was set to $10 \mathrm{ft}^{2} / \mathrm{s}$. The case was simulated for $1 \mathrm{hr}$ using a $1.0 \mathrm{~s}$ time step. Simulations were performed with wetting and drying both enabled and disabled.

MASS2 used a 20 by 109 cell mesh similar to the UNET2D mesh and identical boundary conditions. The Manning coefficient was set to 0.0171, which corresponds to the UNET2D Chezy coefficient at the expected depth. The MASS2 simulation was run for about $1 \mathrm{hr}$ using a $30.0 \mathrm{~s}$ time step.

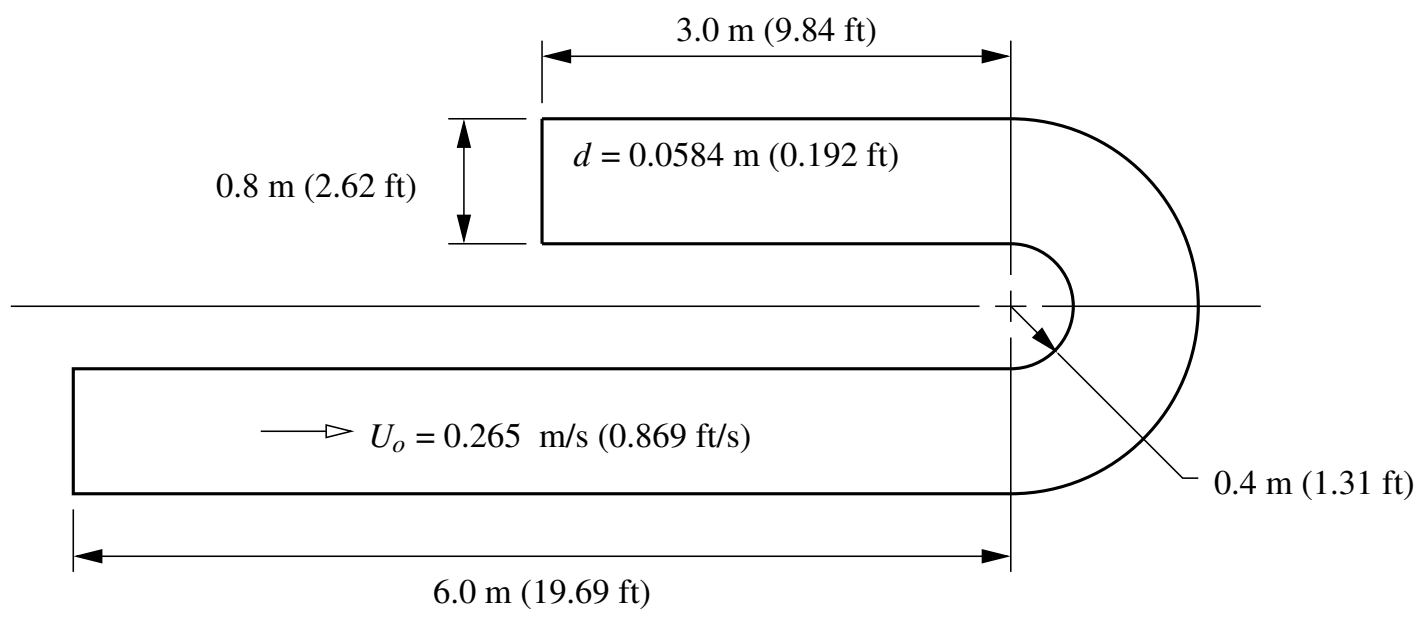

Figure 2.4. Layout of the flow in a 180-degree bend test (planview at laboratory scale).

\subsubsection{Jameson Bend}

Jameson Bend is that part of the Missouri River flowing around Jameson Island near Arrow Rock, Missouri (Figure 2.5). In this reach, management alternatives are being studied to mitigate the loss of shallow water fish habitat due to river bank stabilization activities (USACE 2006). One alternative was the construction of a chute through Jameson Island, exiting and entering the right bank of the Bend.

UNET2D and MASS2 were both applied to this short reach of the Missouri River to qualitatively compare simulated velocity and stage. The two applications shared a mesh and bathymetry so any differences in simulation results should arise from differences in modeling approach (theory and numerical implementation).

The simulated reach had several dikes. Many of the dikes were notched or had varying top elevations which were below the expected water surface elevation. MASS2, at the time of this work, was not able to simulate the overtopping of a dike. To provide a consistent comparison between the two models, the reach was simulated without dikes.

A UNET2D configuration was supplied by Kansas City District personnel. It was run as it was recieved, except that all dikes were removed. Figure 2.6 shows the mesh and bathymetry. A constant stage of $587.0 \mathrm{ft}$ was imposed at the downstream boundary. Discharges imposed at the upstream boundary were $62 \mathrm{kcfs}$ and $2 \mathrm{kcfs}$ in the main and side channels, respectively. The 
Chezy coefficient was 90 and the eddy viscosity was $100\left(\mathrm{ft}^{2} / \mathrm{s}\right.$ assumed) throughout the domain. A $2 \mathrm{hr}$ period was simulated using a time step of $15 \mathrm{~s}$ (several time steps were tried). Wetting and drying was required, so the UNET2D version with wetting and drying enabled was used.

The MASS2 configuration was developed from the UNET2D configuration. The mesh and bathymetry used was extracted from the UNET2D spreadsheet and formatted for MASS2. A Manning's roughness coefficient of 0.029 was chosen so that simulated MASS2 stage was close to that simulated by UNET2D at the upstream boundary. Eddy viscosity was set to $100 \mathrm{ft}^{2} / \mathrm{s}$ throughout the domain as in UNET2D. A period of $6 \mathrm{hrs}$ was simulated with a $30 \mathrm{~s}$ time step and using boundary conditions identical to UNET2D. A dry depth of $0.1 \mathrm{ft}$ and a re-wetting depth of $0.15 \mathrm{ft}$ were used (see Perkins and Richmond 2004a, Section 3.7 for definitions of these parameters).

Two simulations were performed with each model: one without the chute and one with. Chute dimensions and bottom elevations were taken from the UNET2D configuration. Both UNET2D configurations were the same, except that the chute was disconnected from the main domain when it was to be ignored. With MASS2, three small mesh blocks were added to the main channel mesh when the chute was simulated. The mesh for most of the chute was identical to UNET2D. Due to current constraints on MASS2 mesh block connectivity, two small mesh blocks were used to connect the chute mesh to the main channel mesh, as shown in Figure 2.7

An additional MASS2 simulation was performed to illustrate the effect of eddy viscosity on the flow field. The MASS2 configuration without the chute was rerun but with eddy viscosity computed as described in Section 2.1.2 and the results compared with the simulation where eddy viscosity was $100.0 \mathrm{ft}^{2} / \mathrm{s}$. 


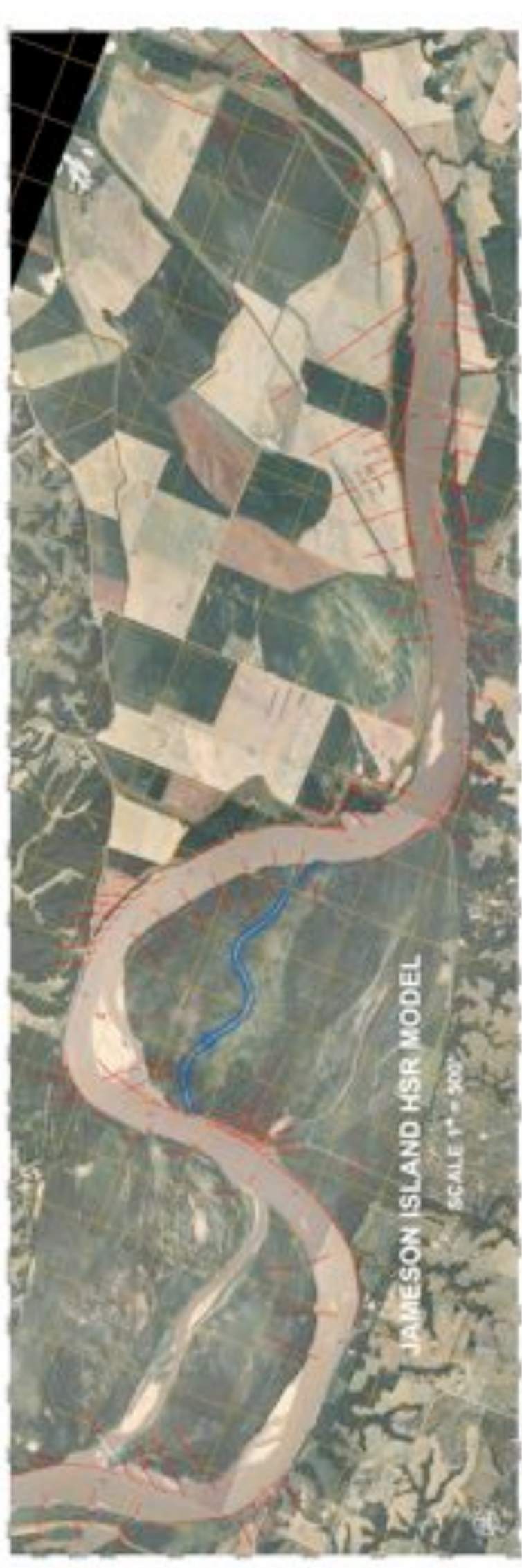

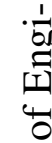

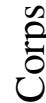

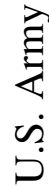

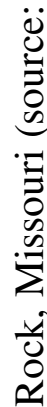

을

छี

.

胥

듬

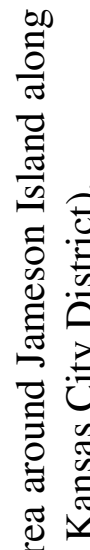

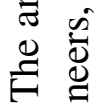

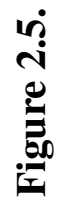




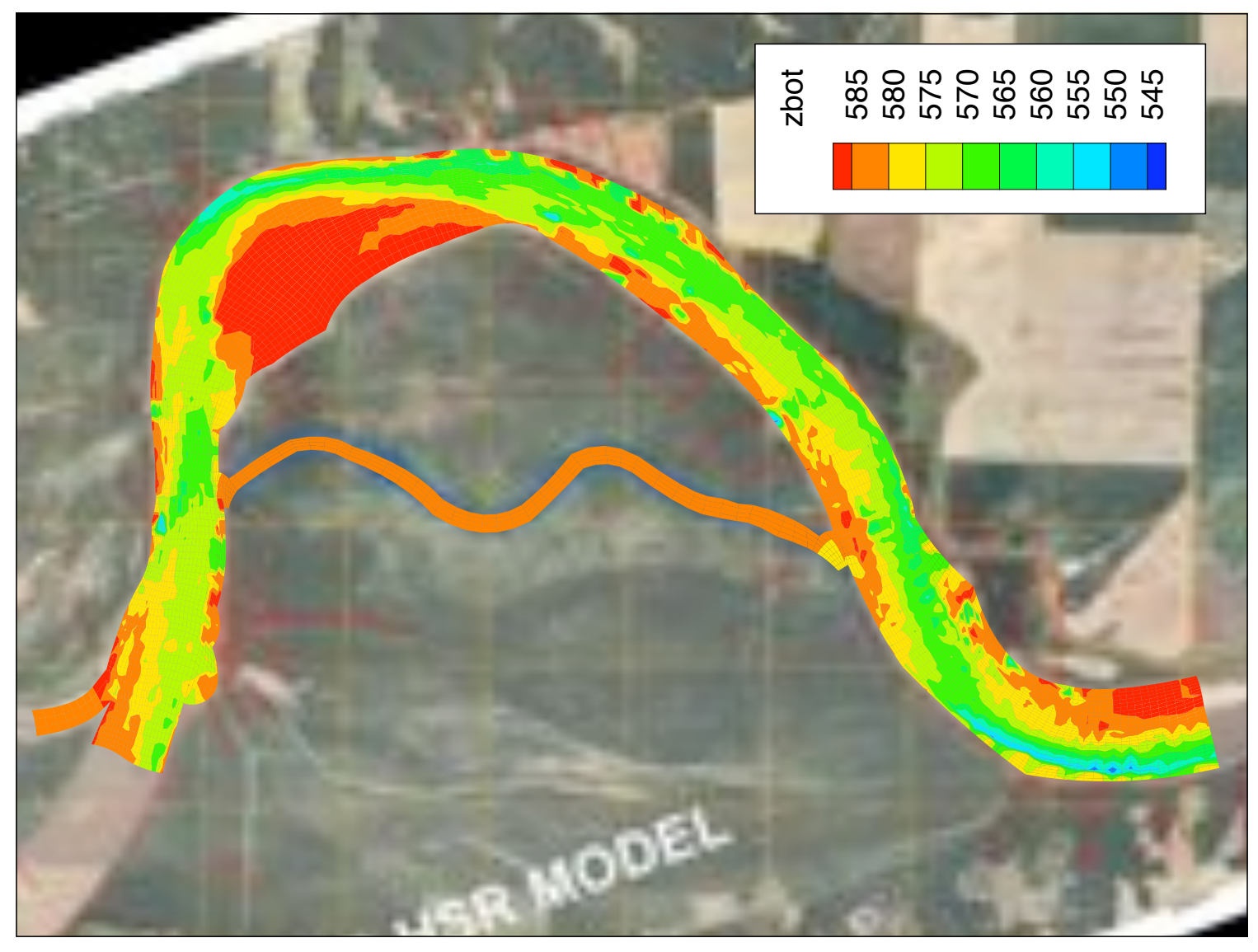

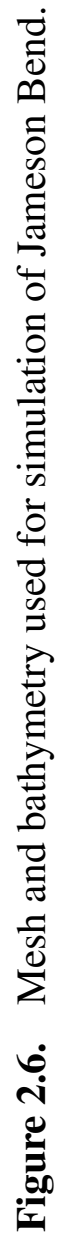

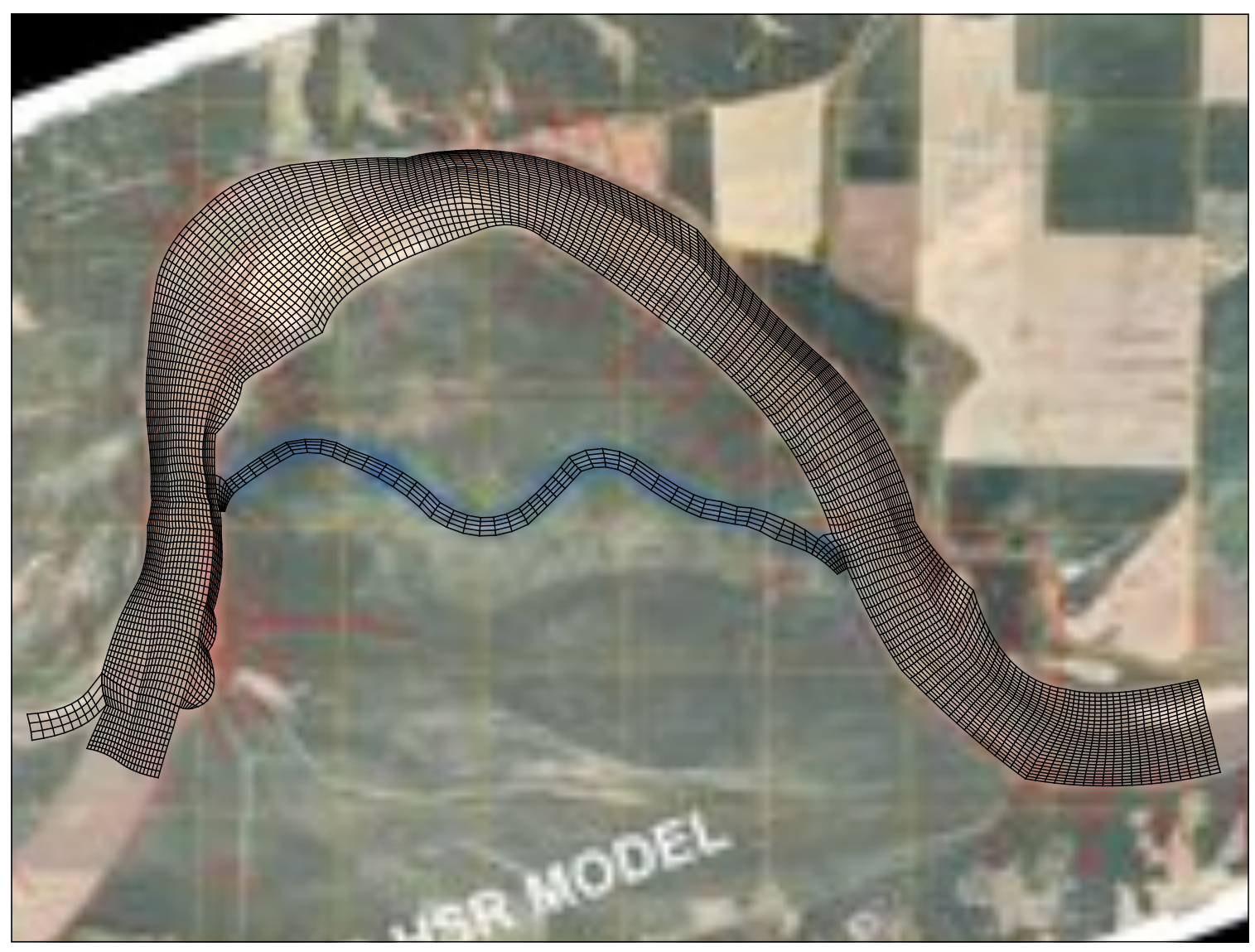




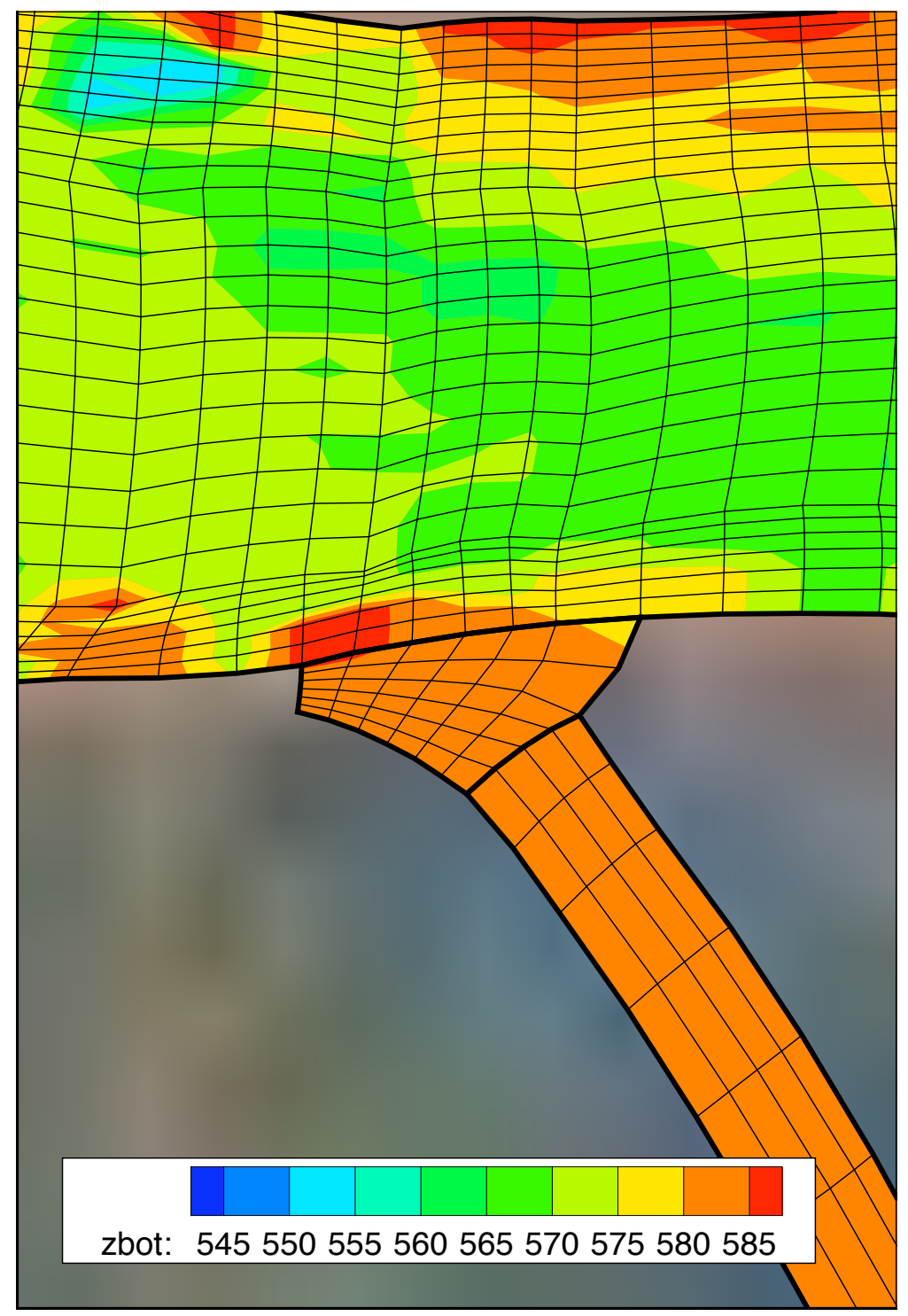

Figure 2.7. MASS2 mesh detail at the upstream end of the Jameson Bend chute. The downstream end of the chute mesh was connected to the main channel mesh in a similar manner. 



\subsection{Results and Discussion}

\subsection{Review of Theoretical Basis and Numerical Methods}

The UNET2D model documentation was reviewed to assess the theoretical basis of the model, numerical methods utilized, and the applicability of the model to analyze river engineering problems of interest to Kansas City District. The theory used in the UNET2D model was compared with that of other 2D depth-averaged models used for similar river flow applications.

In general, the numerical methodology employed in UNET2D is similar to finite-volume methods described in texts such as Patankar (1980) and Ferziger and Perić (2002). However, many of the details, specifically the discrete equations in a curvilinear grid, are derived in a novel way that is not typical of the majority of the literature. No attempt was made here to reproduce the derivation of the governing equations. General observations and some specific questions about the theory and numerical methods are presented in this section. The ability of UNET2D to produce acceptable results was primarily evaluated by examining how well it performed on the series of test cases described in Section 2.2.

\subsubsection{Coordinate System and Governing Equations}

It is not clear whether UNET2D uses global cartesian coordinate system for velocities (and unit discharges) or one wherein the local velocities are oriented along the grid lines (contravariant velocity components as used by (Perkins and Richmond 2004a, Kim et al. 2003). Also, it is not stated whether the grid must be orthogonal (or nearly-so) or whether it can be nonorthogonal.

The continuity equation is derived in the usual way and corresponds to form that is used in other models (e.g Molls and Chaudhry 1995). It does appear that a staggered grid (Patankar 1980) is used where the depth is at the cell center and the velocities are on the cell faces. Is a staggered grid used in UNET2D?

The basic form of the momentum equations (without the apparent centrifugal force) appears to be correct except for the bed friction term which typically is proportional to the velocity component times the magnitude of velocity vector (e.g., Molls and Chaudhry (1995)). This should be checked to see if it is an issue.

The form of the momentum equations applied to a cell with the apparent centrifugal force terms appear to be missing additional cross-terms (proportional to UV). Could this be the reason for the incorrect channel bed results shown in Section 3.5.

It is shown that the UNET2D equations reduce to the expected cartesian form when the grid is not curved. We would recommend that the authors perform a similar exercise would be to demonstrate that the equations reduce to the expected form in a cylindrical coordinate system. That would confirm whether all the additional terms in the equations that arise from the curvature of the coordinates appear as expected.

The effect of turbulence is introduced using the typical Bousinessq eddy viscosity concept to com- 
pute the so-called effective stress terms. However, the normal stress components appear to missing a factor of 2 (see Molls and Chaudhry 1995) and it appears that the equations do not allow for a spatially varied eddy viscosity. Furthermore, it is not consistent to have a formulation that includes separated values of eddy viscosity in the $\mathrm{x}$ and $\mathrm{y}$-directions. Only an isotropic eddy viscosity is consistent with the set of equations being solved.

\subsubsection{Numerical Solution Methods}

A mixture of implicit and explicit finite-difference approximations are used to derive a discretized set of equations. These are consistent with similar models, but some additional discussion should be added to describe the how the advection term in the momentum equations are handled (central differencing versus upwind or higher-order schemes). For example, is any smoothing needed in UNET2D similar to the artificial viscosity approach described by Molls and Chaudhry (1995)?

A variant of the alternating direction implicit (ADI) scheme, called the both directions implicit (BDI), is used to solve the system of linearized equations. This method appears to be appropriate and may have some advantages over the more traditional ADI scheme used by Molls and Chaudhry (1995) and a line-by-line scheme used in the PNNL MASS2 code.

The stability guideline based on the Courant condition is not consistent with that presented by Molls and Chaudhry (1995). In that work there is no requirement for a minimum time step. Some references for use of a minimum time step should be provided. In the test applications we found that UNET2D could be more sensitive to the time step than was expected for an implicit code. The documentation correctly points out that stability is not equivalent to accuracy and there are practical limits to the time step that can be used. Also, the UNET2D document uses "Currant" could this be result of an errant spell checker?

Implementing robust schemes to handle wetting and drying in numerical hydraulic models has long been a challenge. The pilot channel scheme implemented in UNET2D is a novel application of a method that has been successfully used in one-dimensional models such as UNET, CARIMA, and CHARIMA. In two-dimensional models, wetting and drying effects have been modeled most often using either shallow-depth (Falconer and Chen 1991) or a porous-bed (Heniche et al. 2000) schemes. Some discussion of how the UNET2D pilot channel method compares with these other common approaches would be helpful especially given that wetting and drying issues appear to be the cause of some of the problems with the test case solutions.

\subsection{Subcritical, Uniform Flow in a Rectangular Channel}

Table 3.1 shows the UNET2D simulated upstream stage for each downstream stage boundary condition used and for wetting and drying enabled and disabled. The expectation was the upstream stage should match the dowstream stage, indicating friction forces balance gravity.

When wetting and drying was disabled, UNET2D was able to simulate this case adequately. There were some slight differences between upstream and downstream stage, indicating friction was slightly high. This can probably be attributed to an imprecise mesh leading to an imprecise channel slope and channel width. Simulated stages were not affected by the chosen value of eddy 
viscosity.

The UNET2D wetting and drying algorithm had a large and detrimental effect on the results of this test. When depths became shallow friction seemed to be greatly reduced. This effect manifests itself when the depth is less than 5.0 to 7.5 feet. In a "real-world" application, this would mean friction in shallow areas would be reduced, when flow in shallow areas is typically dominated by friction.

Table 3.1. Simulated cases of uniform flow in a rectangular channel with and without wetting and drying (W/D).

\begin{tabular}{cccccc}
\hline \hline Case & $\begin{array}{c}\text { Imposed } \\
\text { Downstream } \\
\text { Stage }\end{array}$ & $\begin{array}{c}\text { Chezy } \\
\text { (ft) }\end{array}$ & $\begin{array}{c}\text { Imposed } \\
\text { Upstream } \\
\text { Discharge } \\
\text { (cfs) }\end{array}$ & $\begin{array}{c}\text { UNET2D Simulated } \\
\text { Upstream Stage } \\
\text { w/ W/D } \\
(\mathrm{ft})\end{array}$ & $\begin{array}{c}\text { w/o W/D } \\
\text { (ft) }\end{array}$ \\
\hline 1 & 2.5 & 106.0 & 2500 & 1.5 & 2.6 \\
2 & 5.0 & 74.9 & 5000 & 4.9 & 5.2 \\
3 & 7.5 & 61.2 & 7500 & 7.7 & 7.7 \\
4 & 10.0 & 53.0 & 10000 & 10.2 & 10.2 \\
5 & 15.0 & 43.3 & 15000 & 15.3 & 15.3 \\
6 & 20.0 & 37.5 & 20000 & 20.3 & 20.3 \\
\hline \hline
\end{tabular}

\subsection{Uniform Flow in a Trapezoidal Channel}

This case could not be simulated with UNET2D. Several downstream stages were tried. The downstream stage was applied both as a constant and starting at a depth well above the bathymetry $(35 \mathrm{ft})$ and ramping down to the desired depth after a warm up period. UNET2D would run only when the downstream stage was well above all bathymetry (i.e. no dry areas). A minimum depth of $5 \mathrm{ft}$ seemed to be necessary. When the downstream boundary condition was constant, the UNET2D simulation would immediately crash. When the downstream boundary was ramped down, UNET2D would simulate the warm up period, but would crash when the channel bank depth became small. As in Section 3.2, this seemed to indicate a problem with UNET2D's wetting and drying algorithm.

\subsection{Flow Around a Spur-Dike}

UNET2D was unable to simulate this test at laboratory scale. Several attempts were made. UNET2D would run, but an extremely small time step was required $\left(\approx 1.0 \times 10^{-4} \mathrm{~s}\right)$, which caused a prohibitively long run time.

Figure 3.1 compares the simulated velocity fields from MASS2 and from UNET2D using eddy viscosities of 2.0, 1.0, and $0.75 \mathrm{ft}^{2} / \mathrm{s}$ from the Froude scaled problem. In each plot of Figure 3.1 a red line separates positive and negative longitudinal velocity. Where this line intersects the $\mathrm{x}$-axis determines the length of the recirculation zone behind the spur dike. With $v_{t}=2.0$, the UNET2D recirculation zone was very small. At $v_{t}=1.0$, the zone was about the right size, but the flow 
separation never seems to re-attach to the boundary. At $v_{t}=0.75$, the recirculation zone grows to the downstream boundary.

The test simulations identified a reasonable value of eddy viscosity that produced a recirculation zone about the right size. Available experimental results also consist of velocity measurements. Further use of this test should include direct comparison of simulation results with measure velocities.

The MASS2 results matched that of the laboratory scale simulation by Perkins and Richmond (2004a), because an eddy viscosity of $2.0 \mathrm{ft}^{2} / \mathrm{s}$ is scaled up from the value used by Perkins and Richmond (2004a), $1.61 \times 10^{-2} \mathrm{ft}^{2} / \mathrm{s}$. 


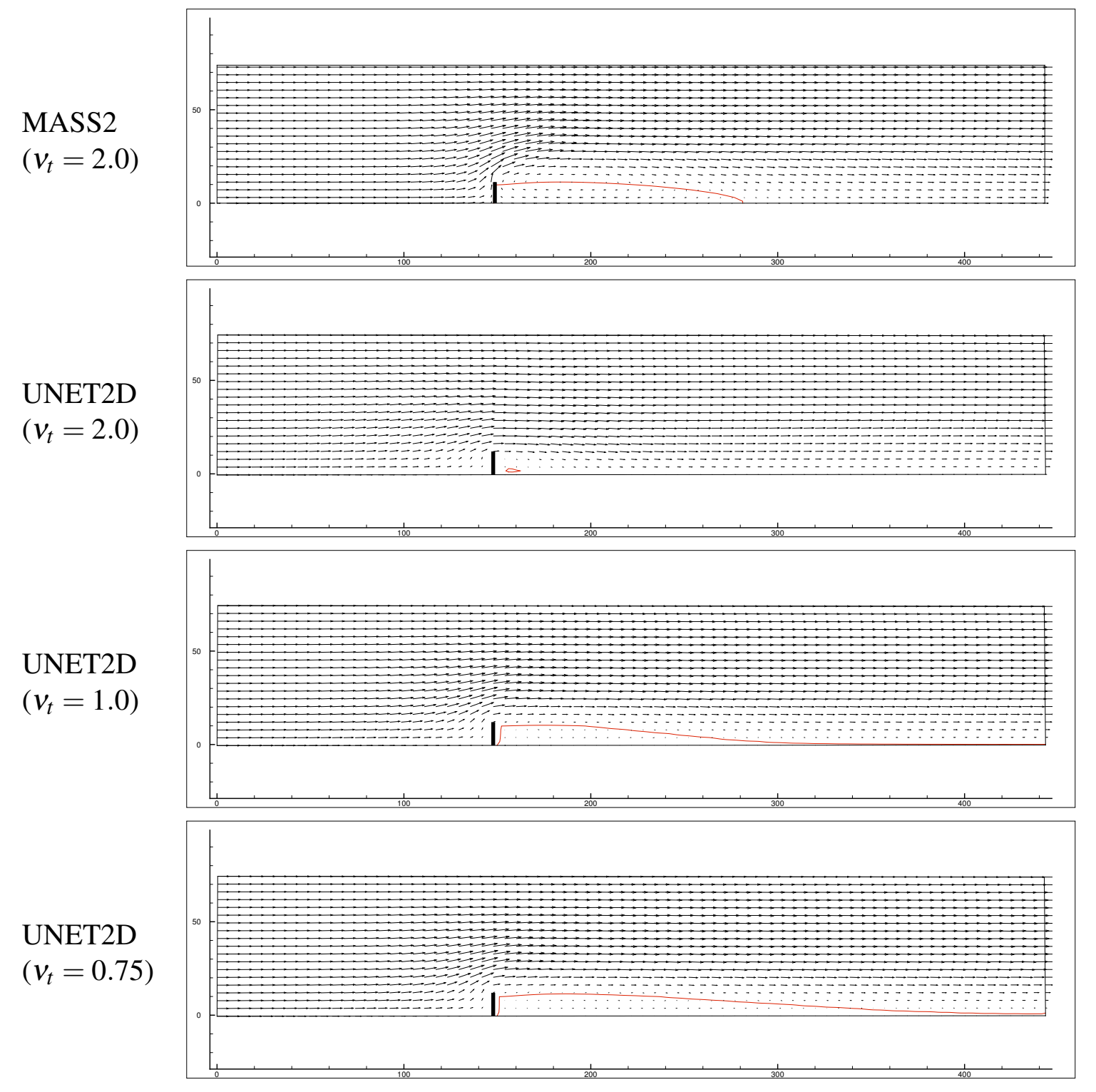

Figure 3.1. Simulated flow around a spur-dike from MASS 2 and UNET2D with various values of eddy viscosity $\left(v_{t}, \mathrm{ft}^{2} / \mathrm{s}\right)$. The red line divides positive and negative longitudinal velocity, identifying the recirculation zone behind the dike. 


\subsection{Flow in a 180-degree Bend}

UNET2D was not able to simulate this case at laboratory scale, due to the shallow depth. UNET2D did run, but produced unrealistic results, regardless of whether wetting and drying was enabled or not.

The UNET2D simulation of this test was generally inconsistent with MASS2 results. Figure 3.2 compares simulated MASS2 and UNET2D (with wetting and drying) depth. Figure 3.3 compares velocity.

UNET2D simulated a much higher head loss in the bend than MASS2. Also, the relative distribution of depth in the bend was quite different. UNET2D simulated a very sharp change in depth at the bend entrance and exit. MASS2 simulated a minimum depth nearly all the way around the inside of the bend, whereas UNET2D simulated a minimum depth about halfway around the bend, where it moved away from the bank and out into the channel. MASS2 simulated a velocity tangential to the bend. UNET2D simulated velocity was tangential at the bend entrance but very different from tangential in the downstream half of the bend.

The UNET2D simulation results were also inconsistent with other 2D depth-averaged simulation results found in the literature. Figure 3.4 compares simulated depth in the bend from Molls and Chaudhry (1995) with that of MASS2 and UNET2D. Figure 3.5 compares simulated velocity. UNET2D simulation results had the same inconsistencies with Molls and Chaudhry (1995) as they did with MASS2 results.

As with the other tests, UNET2D's wetting and drying algorithm had a large effect on the simulation results for this test (Figure 3.6). With wetting and drying enabled, a higher head loss in the bend was simulated (the opposite of its effect in Section 3.2). Velocity direction in the bend was more tangential, but, strangely, velocities in the straight part of the channel were higher along the banks than in the middle. This can be plainly seen at the downstream boundary.

UNET2D did not adequately simulate this problem. The only difference between this test and the rectangular channel test (Section 3.2) was the curved mesh. One must conclude that UNET2D has a problem with non-rectilinear meshes that is likely caused by errors in the formulation of the governing equations (as noted in Section 3.1) 


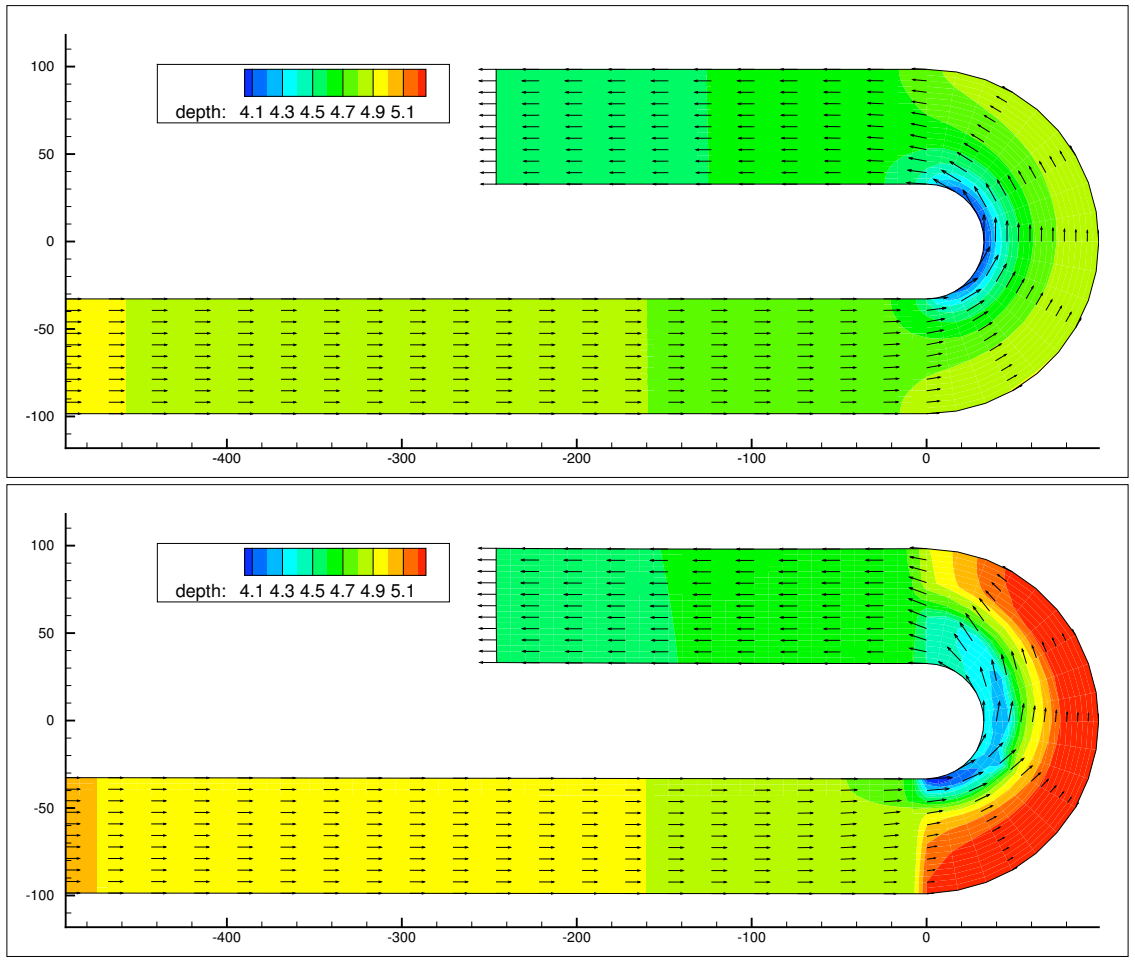

Figure 3.2. Comparison of simulated depth(ft) from MASS2 (top panel) and UNET2D (bottom panel) in the flow in a 180-degree bend test.

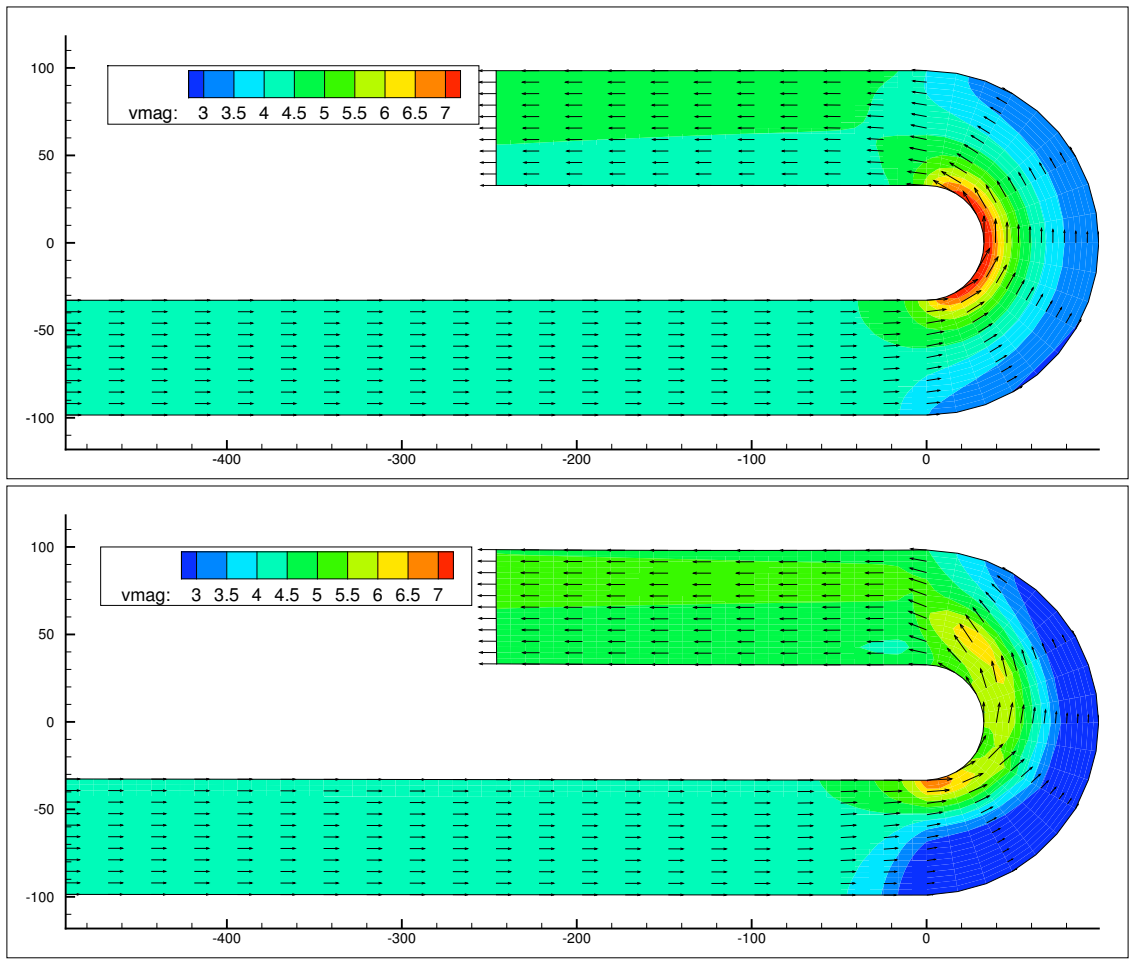

Figure 3.3. Comparison of simulated velocity ( $\mathrm{ft} / \mathrm{s}$ ) magnitude from MASS2 (top panel) and UNET2D (bottom panel) in the flow in a 180-degree bend test. 


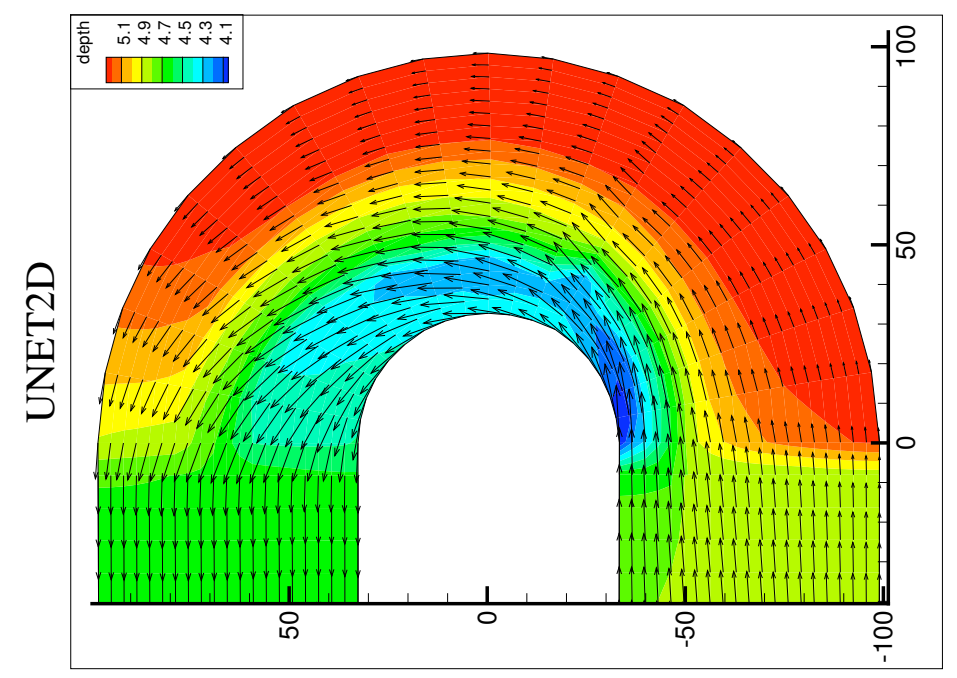

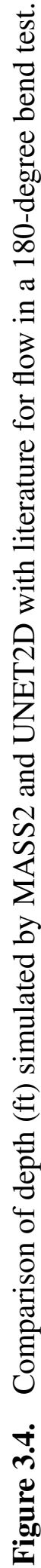

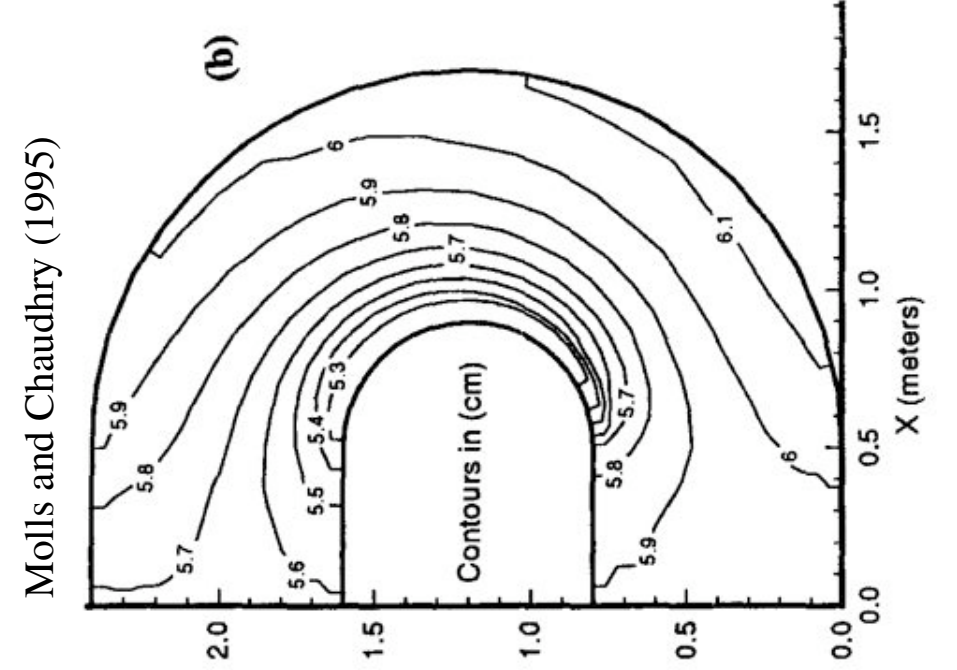

(sมอнew) ᄉ

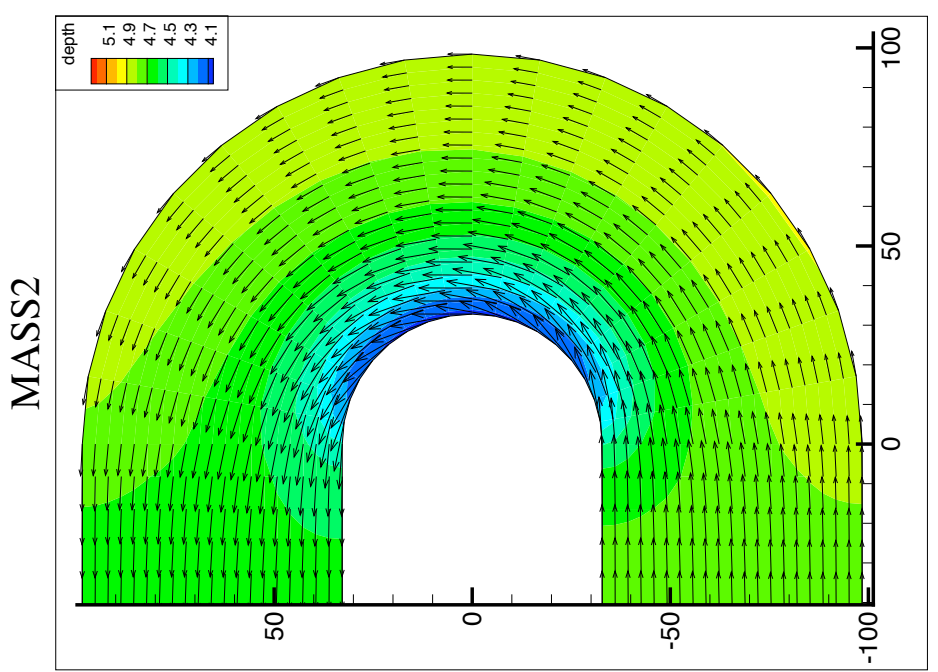




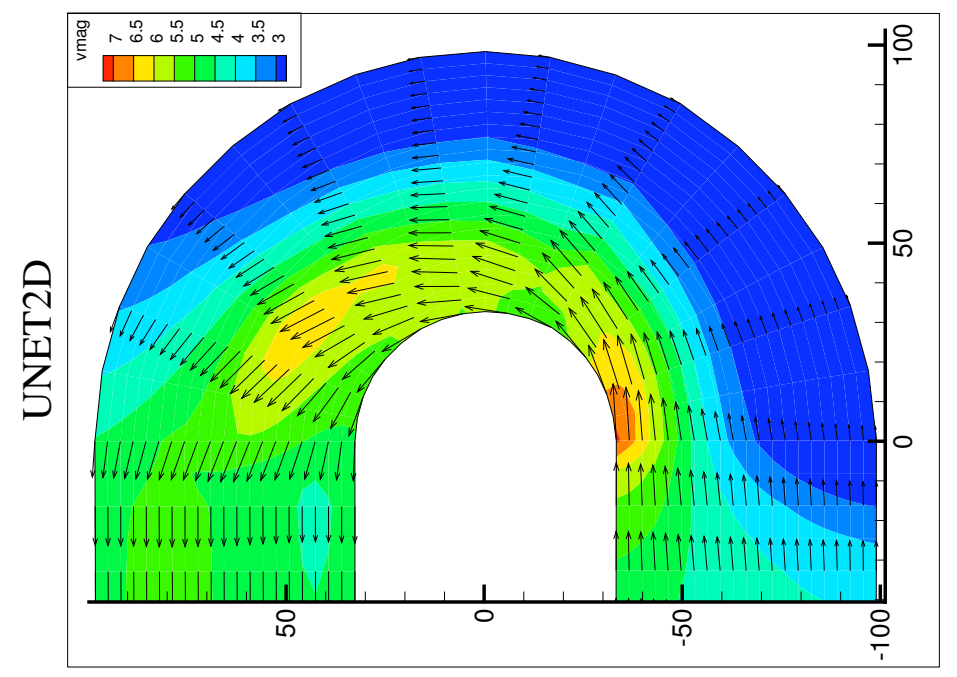

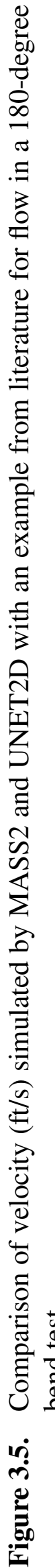
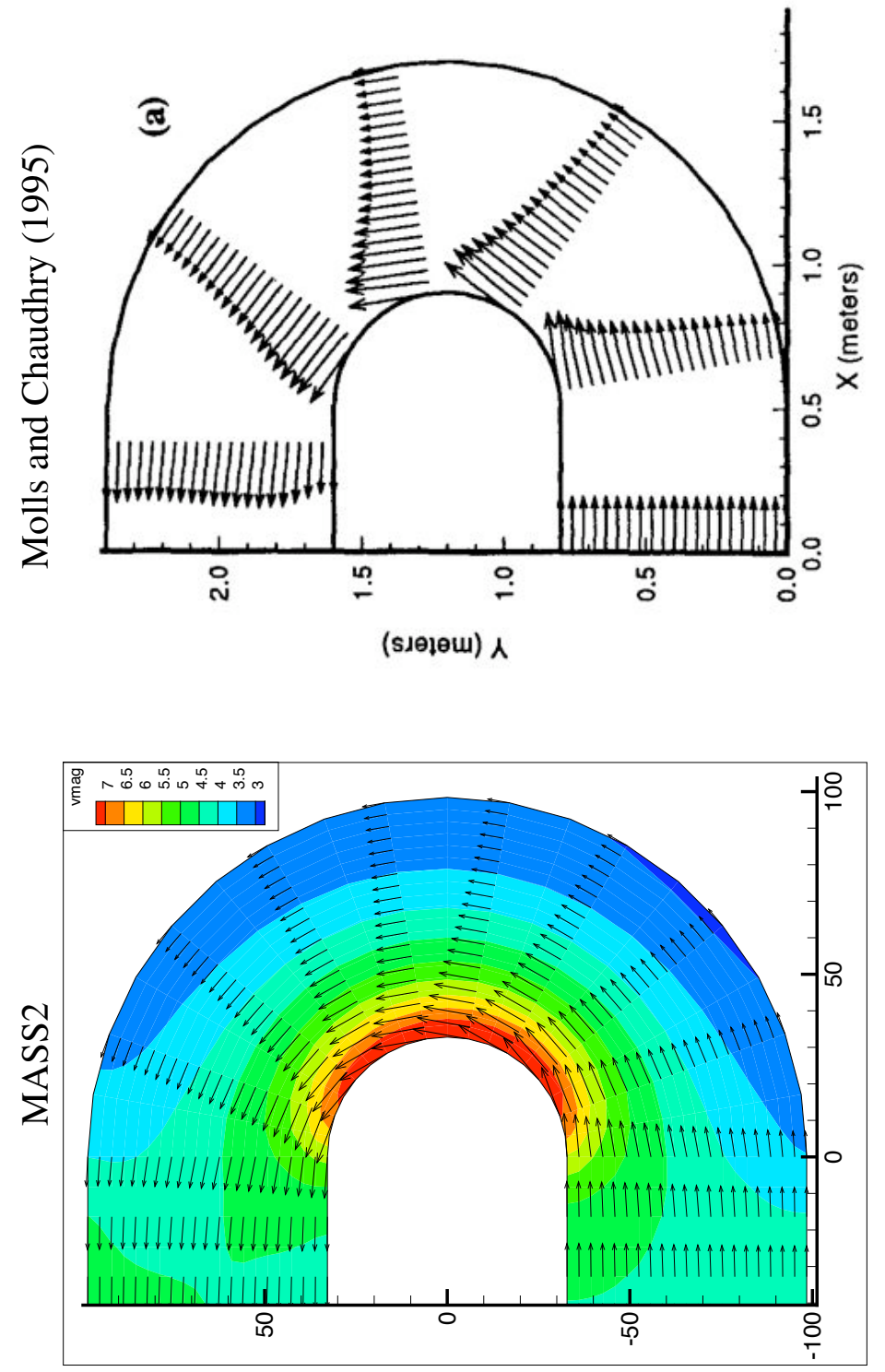


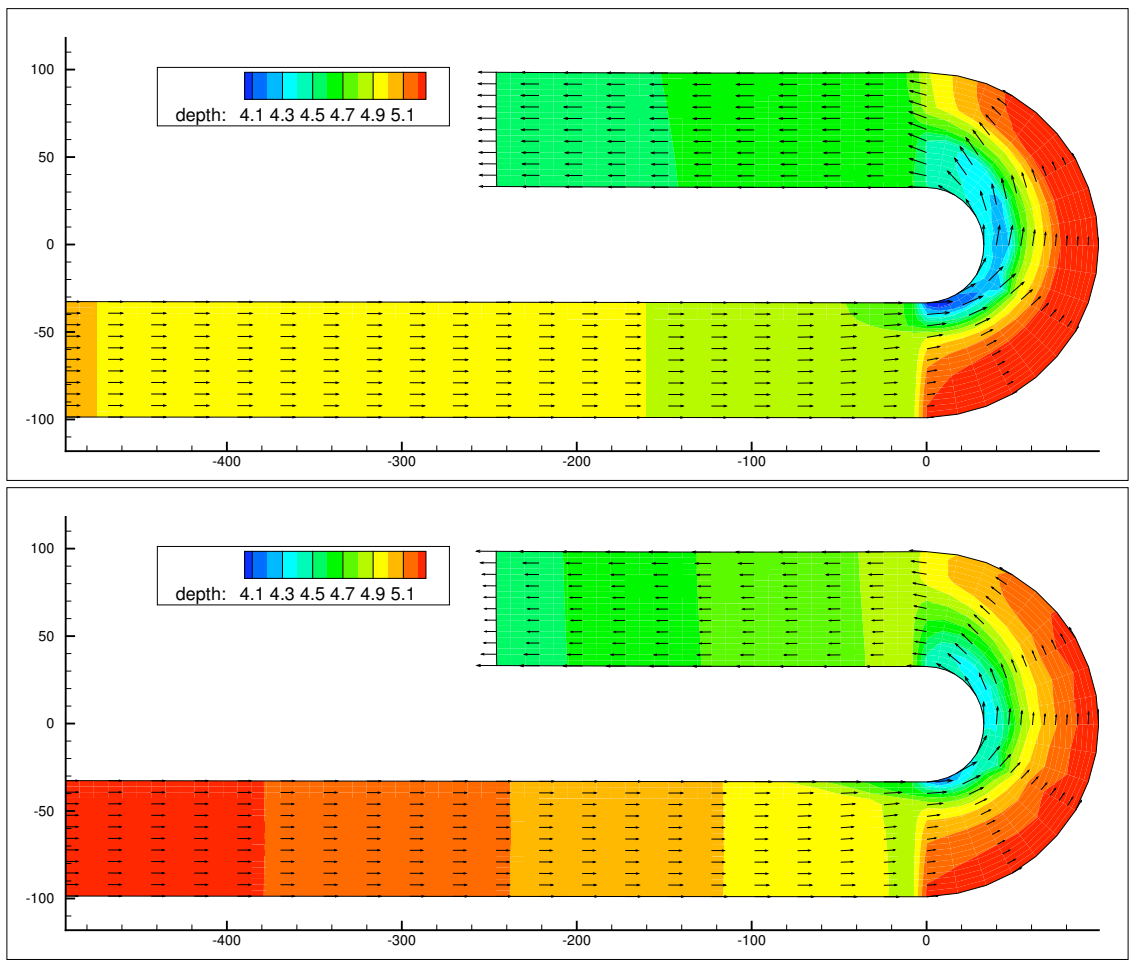

Figure 3.6. Comparison of simulated depth ( $\mathrm{ft}$ ) from UNET2D with wetting and drying disabled (top panel) and with wetting and drying enabled (bottom panel) in the flow in a 180degree bend test. 


\subsection{Jameson Bend}

The UNET2D simulation of Jameson Bend was very sensitive to the selected time step. Simulations would not run with a time step of $30 \mathrm{~s}$ or higher due to instabilities. With time steps of $10 \mathrm{~s}$ or less, unreasonable velocities were simulated where the side channel enters the main channel near the upstream boundary. Even with a $15 \mathrm{~s}$ time step, there were still several areas of unreasonably high velocities (more on this below).

Figure 3.7 compares UNET2D and MASS2 simulation results for Jameson Bend without the planned chute. UNET2D and MASS2 simulated very similar depths and inundated areas. This was expected since the Manning's roughness coefficient in MASS2 was set to produce the same head loss over the simulated reach. Some significant differences in velocity patterns are shown in the results, however. Several numbered circles are shown in Figure 3.7 over the UNET2D simulation results. These highlight some of the major differences.

Circle 1 highlights the main channel at the upstream end of a large bar. UNET2D simulated a much lower velocity in this area than MASS2. There should have been a concentration of flow here as the river diverts around the bar. There is simply no where else for the flow to go. But, UNET2D simulated very little flow here. This raises a concern as to whether mass is conserved in UNET2D.

Circle 2 highlights the area directly upstream of the bar. In this area, MASS2 showed the flow stagnating and beginning to turn around the bar. However, UNET2D simulation results in the same area showed velocities much higher than MASS2, no stagnation and no turning of the flow. Where does this flow shown by UNET2D go?

Circles 3 and 4 highlight two areas on the bar that UNET2D predicts to be dry. Up and downstream of the dry area, a significant velocity was predicted by UNET2D along the right bank where the velocity should have been zero. This also brings doubt on UNET2D mass conservation.

Some other observations can be made about the results shown in Figure 3.7. First, the velocity predicted by MASS2 in the main channel at the bar was much higher than predicted by UNET2D. Second, downstream of the bar, along a given transect, UNET2D generally predicted higher velocities more concentrated in the deeper part of the channel, whereas velocities predicted by MASS2 were more even across the channel. This could be a manifestation of the differences in representation of eddy viscosity in the models, but any such difference should be less pronounced. Finally, UNET2D predicted unreasonably high velocities in several small areas particularly downstream of the bar (see Figure 3.8). These predicted velocities were as high as $18 \mathrm{ft} / \mathrm{s}$ and were not indicated by MASS2 results.

Figure 3.9 compares UNET2D and MASS2 simulation results for Jameson Bend with the chute. The proposed chute appears to have had more effect in the MASS2 simulation than in UNET2D.

The eddy viscosity used in this case was very high relative to other MASS2 river applications and to some measured values (Fischer et al. 1979, Table 5.2). In riverine applications of MASS2, the eddy viscosity used for simulations like Jameson Bend is typically around $0.2 \mathrm{ft}^{2} / \mathrm{s}$. A large 
eddy viscosity value will tend to smear differences in velocity and eliminate or shrink smaller recirculation zones. Sometimes, particularly when aquatic habitat is the issue, the details of the velocity distribution become important.

To illustrate this point, Figure 3.10 compares the velocity field simulated by MASS2 just downstream of the bar. The color contours show the computed eddy viscosity. The black vectors show velocity with the computed eddy viscosity (Section 2.1.2). The red vectors show the velocity with eddy viscosity set to a constant $100 \mathrm{ft}^{2} / \mathrm{s}$. With a large eddy viscosity, the velocity field in a relatively large recirculation zone along the left bank was smeared completely. As expected, velocities are more even across the channel due to the increased mixing of momentum produced by a large eddy viscosity value. 
MASS2
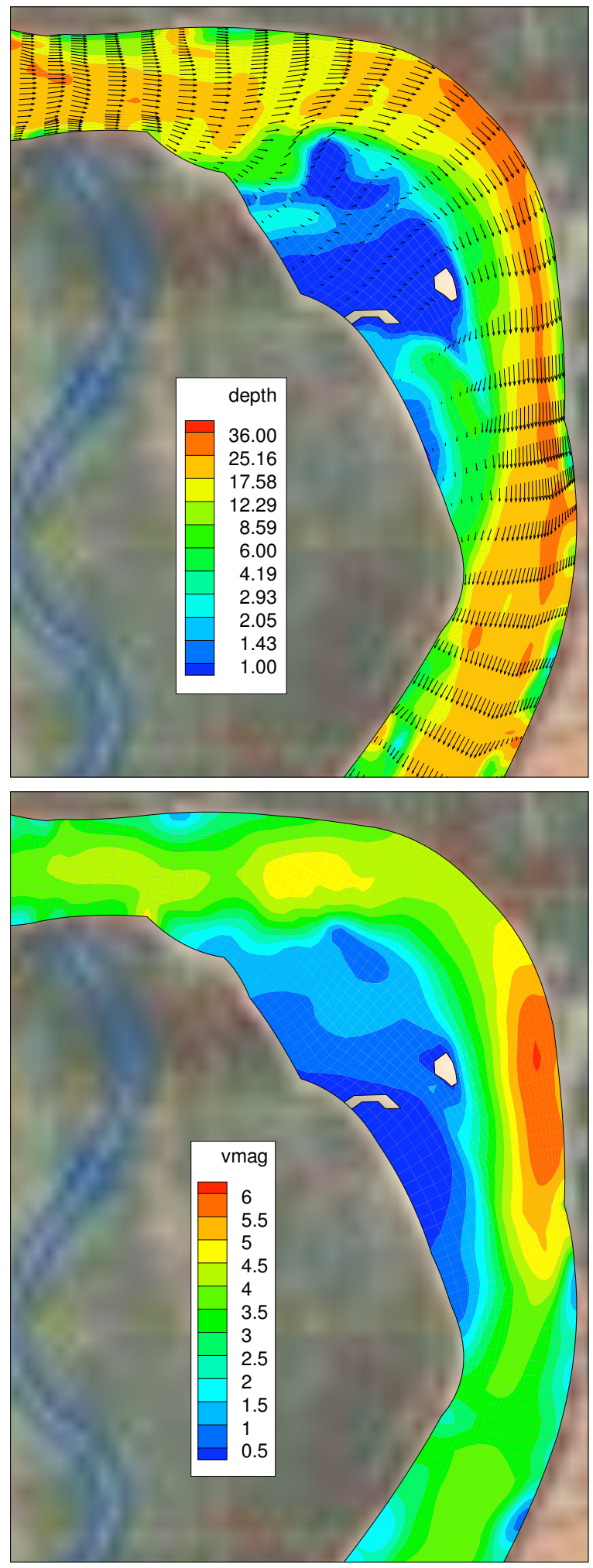

UNET2D
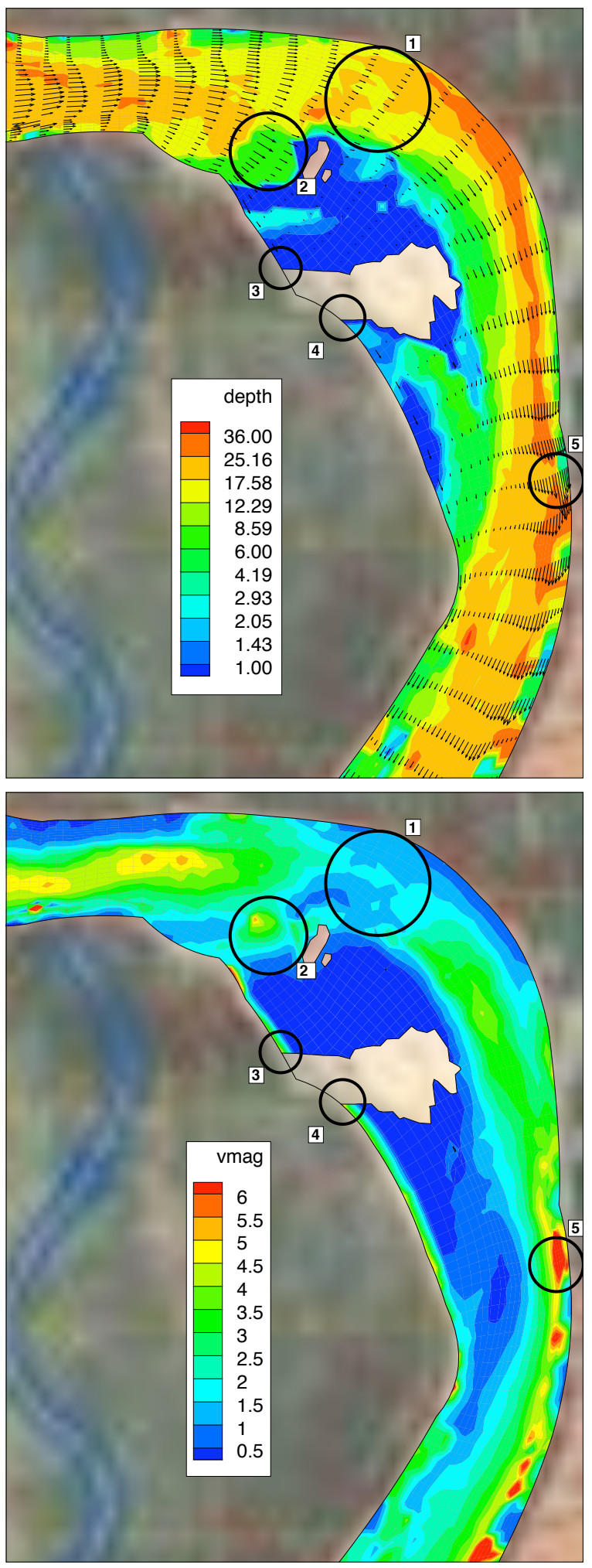

Figure 3.7. Comparison of MASS2 (left) and UNET2D (right) simulated depth (ft, top) and velocity (ft/s, bottom) in the Jameson Bend case. The numbered circles denote areas of interest discussed in the text. 


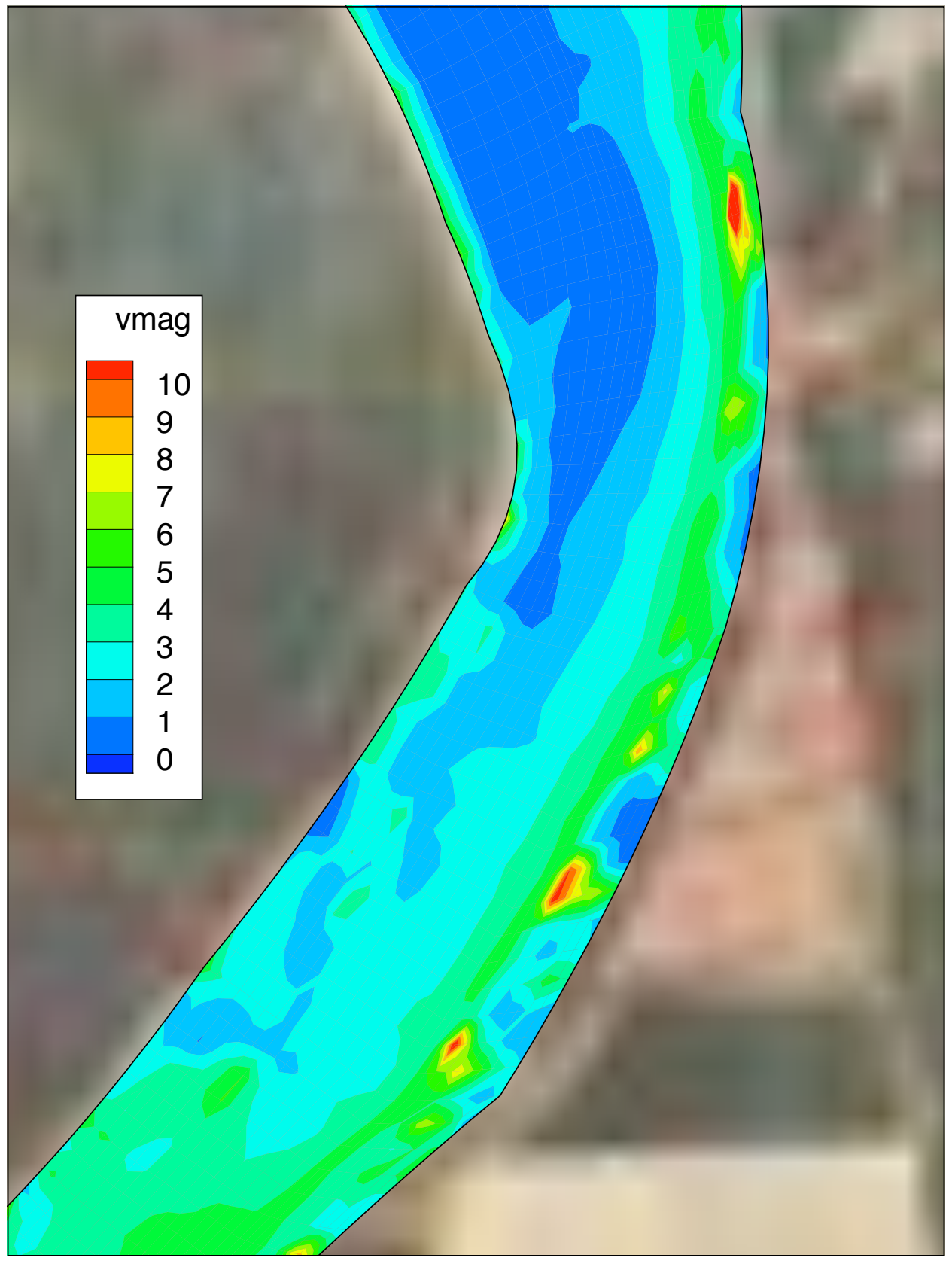

Figure 3.8. Velocity magnitude (ft/s) simulated by UNET2D in the Missouri River downstream of Jameson Island. 
MASS2
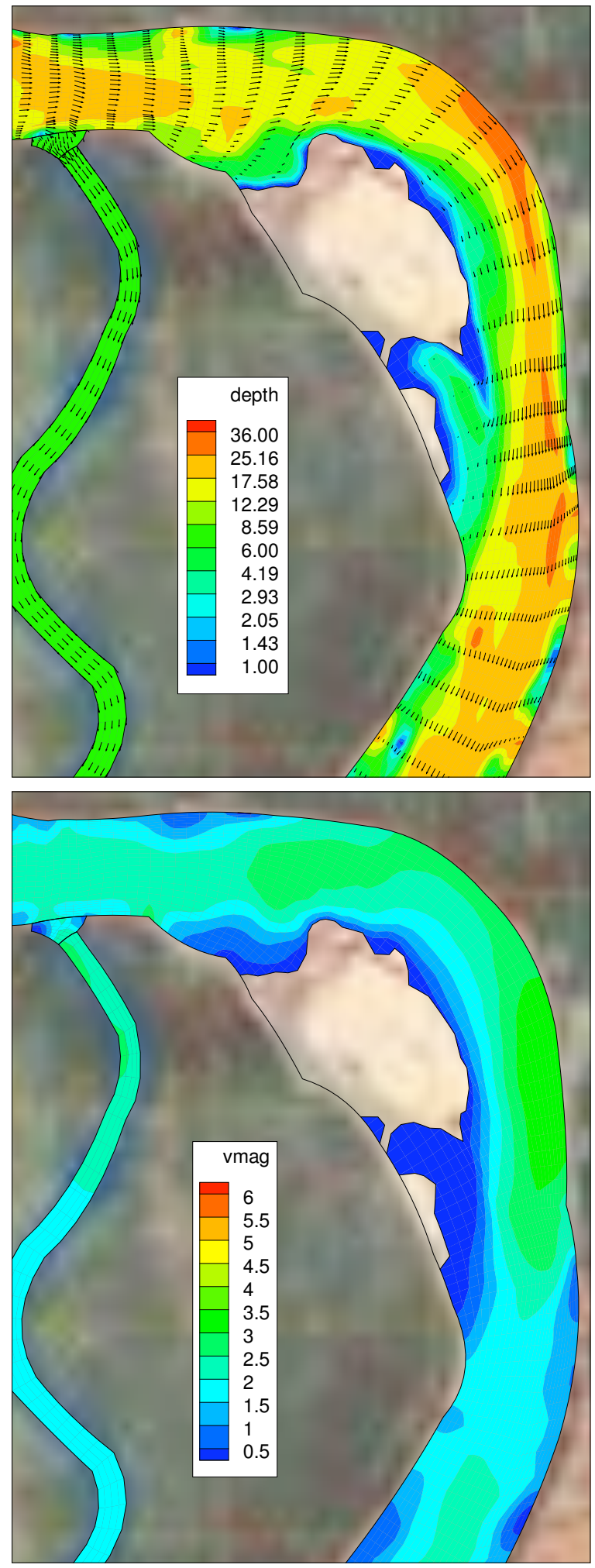

UNET2D
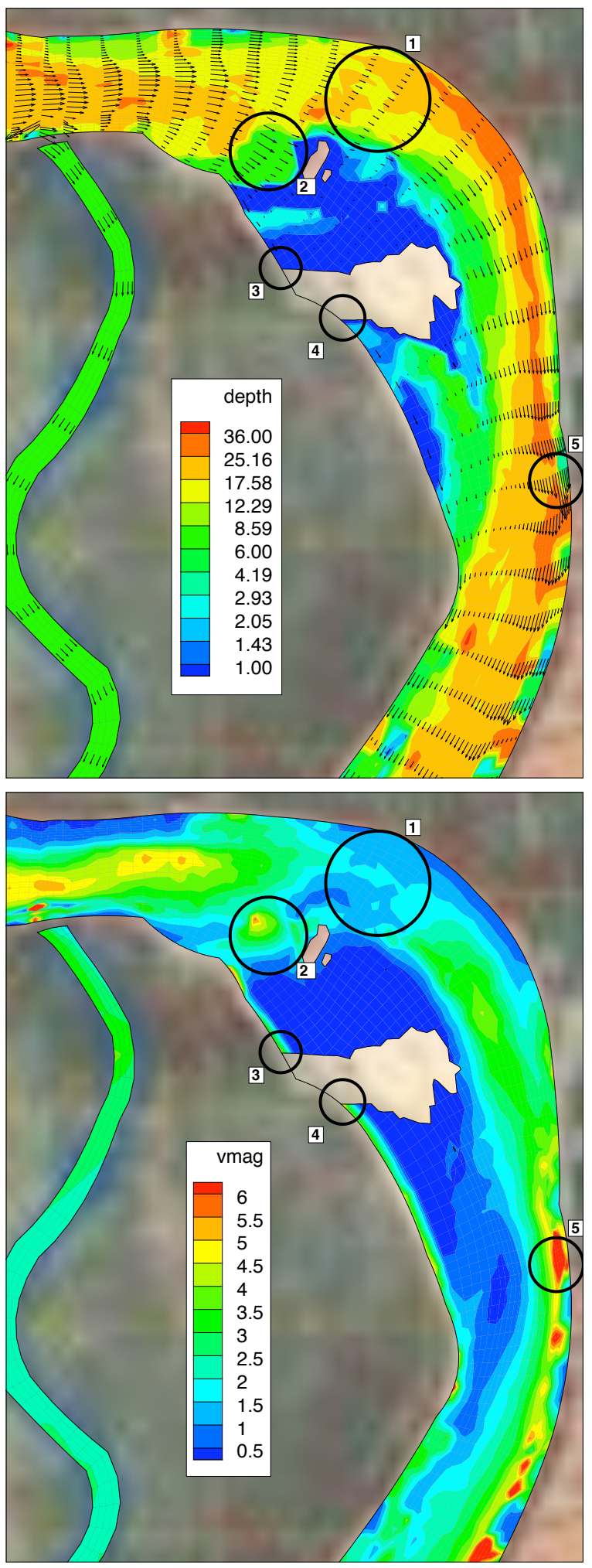

Figure 3.9. Comparison of MASS2 (left) and UNET2D (right) simulated depth (ft, top) and velocity (ft/s, bottom) in the Jameson Bend case (with planned chute). The numbered circles denote areas of interest discussed in the text. 


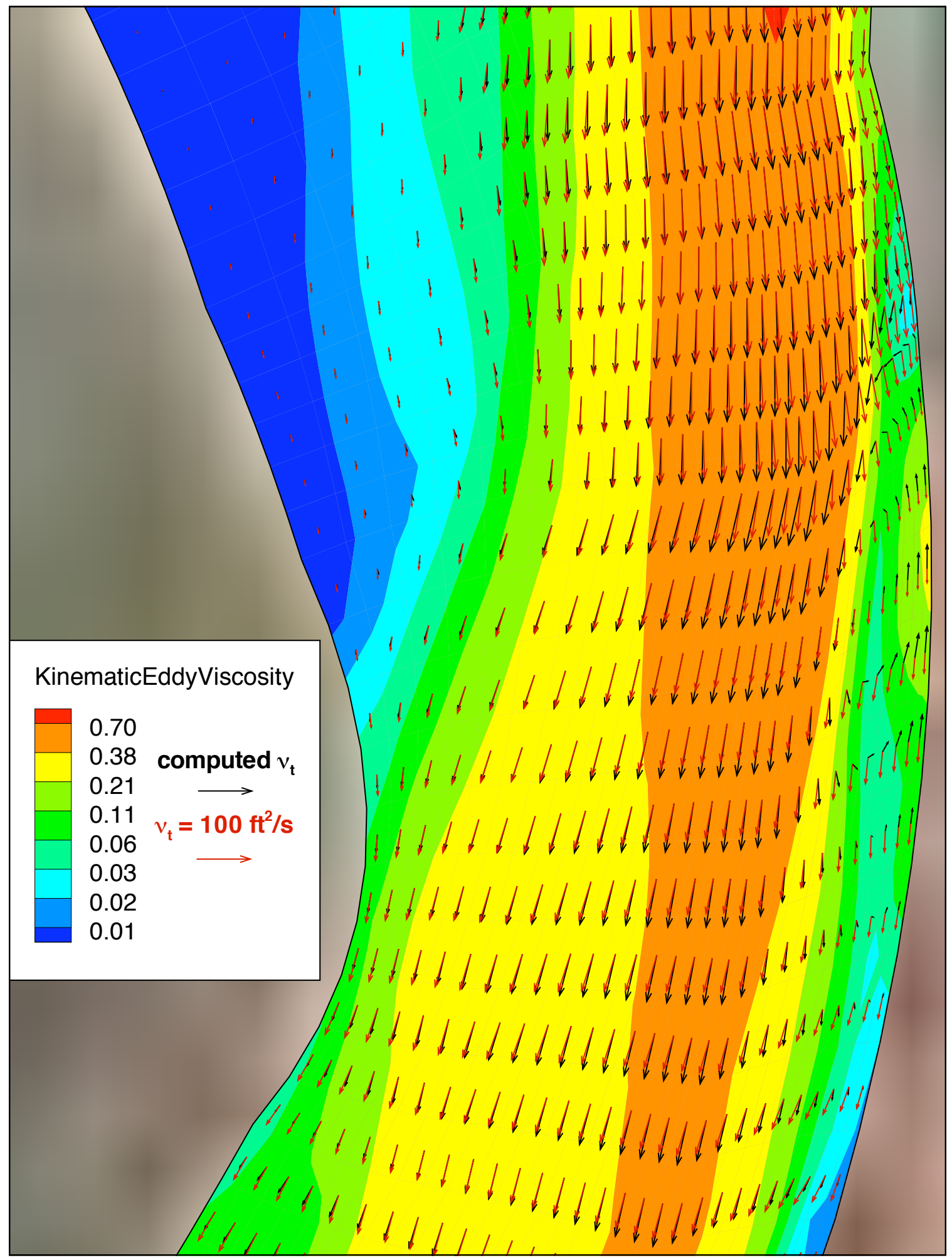

Figure 3.10. Comparison of MASS2 simulated velocity using a computed (equation 2.1p and large constant eddy viscosity $\left(100 \mathrm{ft}^{2} / \mathrm{s}\right)$ in Jameson Bend just downstream of the bar. 


\subsection{Conclusions and Recommendations}

\subsection{Conclusions}

UNET2D uses a set of novel methods to derive, discretize, and solve the 2D depth-averaged equations of fluid flow. If implemented correctly and consistently these methods are expected to yield solutions that would be consistent with those produced by similar 2D depth-averaged hydraulic models. However, several potential problems with the theory and numerical implementation were noted and may be the source of the problems that were encountered with some of the test cases.

UNET2D adequately simulated fluid flow in the subcritical, uniform flow in a rectangular channel test (Section 2.2.1) and the flow around a spur-dike test (Section 2.2.3). In both of these cases, the mesh was rectilinear and consisted of a single loop, the depth was greater than $7.5 \mathrm{ft}$, and wetting and drying was not enabled or not an issue.

In the other tests, fluid flow simulation was problematic. The UNET2D wetting and drying algorithm had a very large, adverse effect on the representation of fluid flow. UNET2D was unable, but should be able, to simulate fluid flow at laboratory scale. The physics are the same in the laboratory as it is in the field. We also noted that UNET2D was very sensitive to the time step and needed to use a value that fell within a narrow range.

We do not recommend the use of the tested version of UNET2D for hydraulic engineering or aquatic habitat studies at this time. We recognize that errors exist in all software and that even commercial software that is extensively tested and widely distributed can have problems. However, the number and nature of the problems with the tested version of UNET2D indicates that further development and testing must be done before the code can be used with confidence.

Based in part on the results shown in this report that were shared in project status meetings, further UNET2D development and testing has been ongoing and some of the problems reported here have been corrected. The code documentation for the theory, numerical methods, and validation cases should be updated and reviewed. An external review may not be required and could possibly be performed by Kansas City District hydraulic engineers that have not been involved in the code development and testing work.

\subsection{Recommendations}

1. A term-by-term comparison of the governing equations in UNET2D with one or more published models should be done to verify that the novel derivation used in UNET2D is consistent with similar models.

Following that step, verify that the UNET2D equations reduce to the expected form in cylindrical coordinates.

2. Further explanation of the allowable time step should be provided and some consideration should be given to having the code perform internal checks and adjustments to keep the time step within a stable range. 
3. A suite of validation problems should be developed and used to validate ongoing changes to UNET2D.

The problems should be simple. They should have known results, either from theory or experiment. To some extent, simulation results should be numerically checked against known results (as was done in Section 3.2.

To some extent, the test cases presented in this work can serve as a starting point, but the validation suite needs to be more rigorous. Test cases should be designed or selected to isolate and test individual capabilities.

4. Some validation problems should be developed to test the effects of mesh quality.

The effects of mesh quality were not investigated in this work, but it remains a very important issue. Tests should be developed that simulate the same problem with different looping strategies and simulate the same problem with "good" and "bad" meshes. The idea of good and bad meshes should explore the effects of mesh skew and orthogonality.

5. UNET2D should be independent of scale, or at least parameterized so that the user is able to apply UNET2D at a various scales.

6. Re-evaluate and consider changing the wetting and drying algorithm.

The representation of dry areas in the domain should not have a large effect the physics of fluid flow.

Following the completion of code testing and validation, the following are suggested improvements that might make UNET2D more flexible and useful for end users:

1. Grid editor

(a) calculate or import mesh (or loops)

i. useful, and important, for simple test simulations

(b) zoom in and out

(c) navigation by using mouse buttons

i. e.g., pan with middle button, zoom with right

(d) export of mesh (entire) image

2. Simulation

(a) Recovery from simulation crashes.

(b) A numerical error, e.g. overrun, crashes the entire interface

(c) Better detection of numerical errors.

(d) A simulation will run, but plotting will cause a numerical error (and crash the interface). 
(e) Be able to do other work in Excel while the simulation is running

\section{Plotting results}

(a) the image used in the grid editor could be used as a background for plotting results too

(b) profile/transect plots of velocity components and magnitude

(c) convenient export of $2 \mathrm{D}$ results to external visualization software (e.g. Tecplot, GIS) 



\subsection{References}

Duan JG. 2004. "Simulation of Flow and Mass Dispersion in Meandering Channels." Journal of Hydraulic Engineering 130(20):964-976.

Falconer RA and Y Chen. 1991. "An improved representation of flooding and drying and wind stress effects in a two-dimensional tidal numerical model." Proceedings of the Institution of Civil Engineers 91:659-678.

Ferziger JH and M Perić. 2002. Computational Methods for Fluid Dynamics, 3rd edition. Springer-Verlag.

Fischer H, EJ List, R Koh, J Imerger, and N Brooks. 1979. Mixing in Inland and Coastal Waters. Academic Press, New York, New York.

Hadian MR and AR Zarrati. 2008. "Application of Multi-Block method for simulating shallow free surface flows in complex geometries." Journal of Hydraulic Research 46(5):668-678.

Hanrahan TP, MC Richmond, EV Arntzen, AM Coleman, KB Larson, WA Perkins, and JD Tagestad. 2007. Effects of Hydroelectric Dam Operations on the Restoration Potential of Snake River Fall Chinook Salmon (Oncorhynchus tshawytscha) Spawning Habitat, Final Report, October 2005-September 2007. PNNL-16944, Pacific Northwest National Laboratory, Richland, WA.

Heniche M, Y Secretan, P Bondreau, and M Leclerc. 2000. "A two-dimensional finite element drying-wetting shallwo water model for rivers and estuaries." Advances in Water Resources 23:359-372.

Kim CW, TH Yoon, YS Cho, and ST Kim. 2003. "A two-dimensional conservative finite difference model in nonorthogonal coordinate system." Journal of Hydraulic Research 41(4):395-403.

Kincaid CT, RW Bryce, PW Eslinger, JM Becker, CA Brandt, AL Bunn, CR Cole, EJ Freeman, GR Guensch, DG Horton, GV Last, TB Miley, WA Perkins, WE Nichols, M Oostrom, MC Richmond, DL Strenge, and PD Thorne. 2001. "Development of a Site-Wide System Assessment Capability." Presented at the Waste Management 2001 Symposium, February 25 - March 1, 2001, sponsored by the University of Arizona, Tuscon, Arizona.

Lien HC, TY Hsieh, JC Yang, and KC Yeh. 1999. "Bend-Flow Simulation Using 2D DepthAveraged Model.” Journal of Hydraulic Engineering 125(10):1097-1108.

McMichael GA, WA Perkins, CJ McMurray, YJ Chien, CL Rakowski, A Coleman, MC Richmond, J Vucelick, EV Arntzen, RP Mueller, CA Duberstein, and J Lukas. 2003. Subyearling Chinook Salmon Stranding in the Hanford Reach of the Columbia River. PNWD-3308, Battelle-Pacific Northwest Division, P.O. Box 999, Richland, Washington 99352. Prepared for Grant County Public Utility District No. 2.

Molls T and MH Chaudhry. 1995. "Depth-Averaged Open-Channel Flow Model." Journal of Hydraulic Engineering 121(6):453-465.

Molls T, MH Chaudhry, and KW Khan. 1995. "Numerical Simulation of Two-Dimensional Flow Near a Spur-Dike." Advances in Water Resources 18(4):227-236. 
Nawachukwu BA. 1979. Flow and Erosion Near Groyne-Like Structures. PhD thesis, University of Alberta, Alberta, Canada.

Ouillon S and D Dartus. 1997. "Three-Dimensional Computation of Flow Around Groyne." Journal of Hydraulic Engineering 123(11):962-970.

Patankar S. 1980. Numerical Heat Transfer and Fluid Flow. Hemisphere, New York, New York.

Perkins W, M Richmond, and G McMichael. 2004. "Two-Dimensional Modeling of TimeVarying Hydrodynamics and Juvenile Chinook Salmon Habitat in the Hanford Reach of the Columbia River." In Critical Transitions in Water and Environmental Resources Management, Proceedings of the 2004 World Water and Environmental Resources Congress, June 27-July 1, Salt Lake City, Utah, Sehlke G, DF Hayes, and DK Stevens, eds. Reston, Virginia. ASCE.

Perkins WA and MC Richmond. 2004a. MASS2, Modular Aquatic Simulation System in Two Dimensions, Theory and Numerical Methods. PNNL-14820-1, Pacific Northwest National Laboratory, Richland, Washington.

Perkins WA and MC Richmond. 2004b. MASS2, Modular Aquatic Simulation System in Two Dimensions, User Guide and Reference. PNNL-14820-2, Pacific Northwest National Laboratory, Richland, Washington.

Rajaratnam N and Nwachukwu. 1983. "Flow Near Groyne-like Structures." Journal of the Hydraulics Engineering 109(3):463-480.

Rakowski CL, WA Perkins, MC Richmond, and JA Serkowski.. 2008. Determining John Day Project Tailrace and Forebay Zones Using the MASS2 Model. Memorandum for Record. PNNLSA-60840, Pacific Northwest National Laboratory, Richland, WA.

Rakowski CL and MC Richmond. 2001. Dalles Tailwater Predator Study: Numerical Analysis of Tailwater Flow Conditions. PNNL-13594, Pacific Northwest National Laboratory, Richland, WA.

Rakowski CL and MC Richmond. 2003. John Day Tailrace MASS2 Hydraulic Modeling. PNNL14491, Pacific Northwest National Laboratory, Richland, WA.

Richmond M, W Perkins, and Y Chien. 2000. Numerical Model Analysis of System-wide Dissolved Gas Abatement Alternatives. PNWD-3245, Battelle Pacific Northwest Division, P.O. Box 999, Richland, Washington, 99352. Prepared for the U.S. Army Corps of Engineers, Walla Walla District under Contract DACW68-96-D-0002.

Richmond M, W Perkins, and C Rakowski. 1999a. Two-Dimensional Analysis of Flow Conditions and Sediment Mobility in the Lower Snake River for Impounded and Natural River Conditions. U.S. Department of Energy, Pacific Northwest National Laboratory, P.O. Box 999, Richland, Washington. Prepared for the U.S. Army Corps of Engineers, Walla Walla District.

Richmond M, W Perkins, and T Scheibe. 1999b. Two-Dimensional Hydrodynamic, Water Quality, and Fish Exposure Modeling of the Columbia and Snake Rivers. Part 1: Summary and Model Formulation. Final Report, Battelle Pacific Northwest Division, P. O. Box 999, Richland, Washington, 99352. Prepared for the U.S. Army Corps of Engineers, Walla Walla District under Contract DACW68-96-D-0002. 
Richmond M, W Perkins, and T Scheibe. 1999c. "Two-Dimensional Simulation of Hydrodynamics, Water Quality, and Fish Exposure in the Columbia/Snake River System." In Proceedings of WaterPower99.

Rozovskii IL. 1957. Flow of Water in Bends of Open Channels. Academy of Sciences of the Ukrainian SSR, Kiev. (translated from Russian by the Israel Program for Scientific Translations, Jerusalem, 1961).

Spasojevic M and F Holly Jr. 1990. "2-D Bed Evolution in Natural Watercourses New Simulation Approach.” J. of Waterway, Port, Coastal, and Ocean Engineering 116(4):425-443.

Tingsanchali T and S Maheswaran. 1990. "2-D Depth-Averaged Flow Computation near Groyne." Journal of Hydraulic Engineering 116(1):71-86.

USACE. 2006. Jameson Island Unit, USFWS Big Muddy Fish and Wildlife Refuge, Chute Construction Project. Project Implementation Report, U.S. Army Corps of Engineers (USACE), Kansas City District, 700 Federal Building, Kansas City, MO 64106-2896. Accessed February 19, 2009 at http://www.nwk.usace.army.mil/projects/mitigation/projnews/ JamesonIsPIRPart 1. pdf.

Zhou J. 1995. "Velocity-Depth Coupling in Shallow-Water Flows." J. of Hydraulic Engineering 121(10):717-724. 


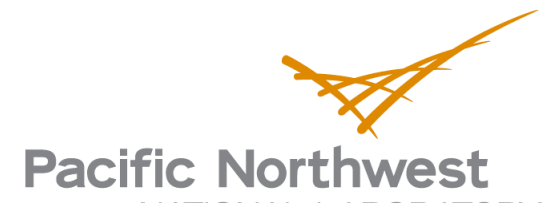

NATIONAL LABORATORY

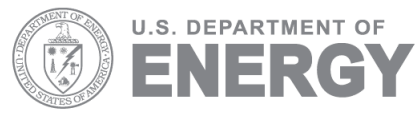

902 Battelle Boulevard

P.O. Box 999

Richland, WA 99352

1-888-375-PNNL (7665)

www.pnl.gov 